\title{
Repercusiones españolas de la Revolución de 1830
}

ALBERTO GIL NOVALES

Universidad Complutense de Madrid

«La Revolución francesa de 1830 abrió los pechos a la esperanza de la libertad». Así comenzaba Manuel Núñez de Arenas en 1927 su artículo sobre «La expedición de Vera en $1830{ }^{1}$, trabajo que sigue siendo hoy por hoy el único importante sobre la influencia de la revolución de ese año en España; y esto a pesar de que el autor advertía lealmente de que nuevas investigaciones contribuirían sin duda a trazar un cuadro más completo de los sucesos. Contribución a ese cuadro más completo pretende ser también el presente artículo.

1 Reproducido en Manuel Núñez de Arenas: L'Espagne des Lumières au Romantisme. Etudes réunies par Robert Marrast, París, Centre de Recherches Hispaniques, 1963, pp. 243-291. Para la historia de la expedición de Vera es también fundamental AHN, Estado, leg. 3060. 
Cronológicamente la Revolución sorprendió a España en la última etapa del reinado de Fernando VII, en lo que hoy llamamos «la década ominosa», que desde el punto de vista liberal se halla llena de deseos de desquite, de conjuraciones y de insurrecciones, y ante su fracaso, de víctimas. Los acontecimientos franceses y europeos de 1830 sirvieron de estímulo y ejemplo para los revolucionarios españoles, mucho más de lo que hasta ahora hemos supuesto, y también lógicamente se trató de aprovechar lo que parecía una coyuntura favorable en Francia. Lo que Luis XVIII había destruido en España bien podía remediarlo Luis Felipe, pues Francia había pasado de ser la patria de la reacción a serlo otra vez de la libertad. Si a pesar de ello no hubo en España revolución de 1830 o de 1831 se debió no tanto a la actitud cautelosa del Orléans, sino a las terribles divisiones internas de los revolucionarios españoles, que a pesar de los intentos repetidos de lograr la unidad, se odiaban entre ellos probablemente más que al poder absoluto, y esto por razones personales, e ideológicas; y en segundo lugar el fracaso de las conjuraciones e insurrecciones se debió a que todas ellas se hallaban infiltrádas por agentes del Gobierno, de manera que éste estaba al tanto absolutamente de todo, y dejaba hacer, y descargaba sus golpes, en el momento más oportuno para sus intereses. Aun así sorprende el entusiasmo y la confianza en las conjuraciones: después de cada fracaso, atribuido con frecuencia entre los mismos liberales a los espías del poder, prosigue la intentona, la preparación del próximo acto, mezclado con una dosis muy grande de desconfianza en el prójimo, que puede ser el delător de turno. Los propios servicios de policía difunden especies falsas sobre determinados patriotas, para sembrar la duda, y hacer imposible la acción. Pero si después de tantas víctimas y tantos fracasos prosigue la conjuración, y su ramificación por todos los rincones de España, el hecho significa que el régimen político del absolutismo se mantiene sólo por inercia, y basta un accidente como el de la muerte de Fernando VII para que de la noche a la mañana España aparezca como liberal; pero también las circunstancias de la oposición al absolutismo explican que este cambio no implique una profunda revolución social.

En torno a 1830 los protagonistas de la siempre intentada revolución española pertenecen a la vez a la emigración y al interior del país. Del exterior parten por regla general todas las iniciativas, aunque las difíciles circunstancias de la vida en el corazón de España hacen que el intento de control desde fuera con frecuencia sea sólo teórico, y que los elementos del interior gocen de una gran autonomía, incluso a nivel de 
decisión política. El primer conato liberal de la década de que tenemos noticia es el protagonizado por el Coronel Francisco Valdés, quien partiendo de Gibraltar el 3 de agosto de 1824 se apoderó de Tarifa. Derrotado por inconexión con los conjurados del interior, Valdés pudo salvar la vida, y le volveremos a encontrar en la expedición de Vera en 1830; pero el intento aumentó el panteón español de mártires por la libertad con nombres como los de Benigno Morales, antiguo redactor del Zurriago, Carlos Maisof -es decir el aventurero francés Cugnet de Montarlot- y Pablo Iglesias. Siguieron otros intentos, en Cartagena, el propio año 1824, terminado también en fusilamientos, o el desembarco en Guardamar, cerca de Alicante, de los hermanos Antonio y Juan Fernández Bazán, con el Teniente Coronel José Sellés, que terminó también desastrosamente.

Desde marzo de 1824 , por lo menos, o con mayor eficacia desde 1825, se hallaba conspirando el General, antiguo guerrillero, D. Francisco Espoz y Mina, pero, en esta época de su vida, como en todas, sus acciones resultan harto sospechosas. Sin necesidad de remontarnos a los inicios de Espoz como guerrillero, a su conducta en el trienio liberal y a su entrega de la plaza de Barcelona a los franceses en 1823, señalemos su contacto epistolar con la siempre ambiciosa Carlota Joaquina, de que habló Bowring ${ }^{2}$, y las gestiones que llevó a cabo Juan Olavarría y por delegación el fraile Juan de Mata Echevarría ${ }^{3}$ cerca del mismo Fernando VII. Aunque parece ser que en estas conversaciones Olavarría, personaje de una pieza, agente de aduanas en Irún en 1821 y jefe de los servicios de información españoles en la frontera ${ }^{4}$, que en 1822 había intentado, de acuerdo con Fabvier, sublevar al ejército francés llamado de observación ${ }^{5}$-el que iba a invadir España-, aunque Olavarría, digo, fue más allá de lo que Mina quería, siempre queda como positivo el acuerdo entre los dos para negociar incluso con los partidos moderado y apostólico. Julio Puyol, que historió estas andanzas ${ }^{6}$, no

2 Sir John Bowring: Autobiographical Recollections, London, Henry S. King and Co., 1877, pp. 319-22.

3 Este había usado el nombre masónico de Ganganeli (!). Cf. lista cit. en nota 145.

4 Cf. El Espectador, M., n. ${ }^{\circ}$ 77, 30 junio 1821, y Pedro Ortiz Armengol: Aviraneta y diez más, M., Prensa Española, 1970, p. 113.

5 Cf. Eduard Guillon: Les Complots militaires sous la Restauration, París, Plon, 1895, p. 273, y A(ntoine) Debidour: Le Général Fabvier, París, Plon, 1904, p. 189. Guillon confunde a Olavarría con Olavarrieta, es decir Clara-Rosa.

6 Julio Puyol: La conspiración de Espoz y Mina (1824-1830), M., Tip. de Archivos, 1932. Cf. p. 63 (utilización de todos los partidos). Tampoco José María Iribarren: Espoz y Mina el liberal, M., Aguilar, 1967, conoce a Marco-Artu. 
conoció la etapa ulterior y más granada, centrada en torno a la figura de Agustín Marco-Artu, y de sus continuadores.

\section{Marco-Artu}

Agustín Marco-Artu y Acha, oficial impurificado de ingenieros y arquitecto, autor de un proyecto de navegación del Tajo que manuscrito conserva nuestra Biblioteca Nacional ${ }^{7}$, es la figura central de un vasto proyecto de insurrección que se hallaba a punto de estallar cuando Calomarde, Ministro de Justicia, el 16 de marzo de 1831 ordenó la detención de los principales implicados. Podemos reconstruir el alcance de lo proyectado gracias a la causa de $\mathrm{D}$. Antonio Miyar, el librero y bibliógrafo liberal, que por hallarse de visita en casa de Marco-Artu el día en que se intentó la detención de éste, 17 de marzo de 1831, fue implicado por los jueces en el asunto, con el que al parecer nada tenía que ver, y ahorcado poco después. La causa, publicada por Pascual Madoz en 1863 , resulta de riqueza extraordinaria, aunque hasta ahora había pasado inadvertida para los historiadores ${ }^{8}$. Los documentos Marco-Artu del Ministerio de Justicia y los papeles Lafayette de la Biblioteca Nacional completan las fuentes principales de nuestro estudio.

La orden de detención, firmada por Calomarde, atañía no sólo a Marco-Artu, sino al médico D. Victoriano Torrecilla y a su hermano, y al abogado Olózaga. En su virtud, el Alcalde de Corte D. Antonio María Segovia practicó la prisión de D. Salustiano de Olózaga; D. Alfonso de Cavia, la de D. José Torrecilla; y el también Alcalde D. José Zorrilla - padre del futuro poeta - apresó a Miyar, mientras Marco-Artu se le escapaba por los tejados, gracias a los gritos de advertencia que lanzó

7 Agustín Marco-Artu: Croquis del Curso de las aguas del Río Tajo desde Aranjuez hasta Portugal con la indicación de sus obstáculos naturales y accidentales y la expresión de las obras que deben practicarse en él para realizar su navegación. Ejecutado por encargo del Brigadier de Infantería D. Francisco Javier de Cabanes por El Arquitecto de la Real Academia de San Fernando D. de Abril, Mayo y Junio de 1828. (BN Madrid, ms. 76.) en los meses

8 (Pascual Madoz e Ibáñez): «Causa Formada en el año 1831 en virtud de Real orden por el Sr. Gobernador de la Sala de Alcaldes de Corte, Don Estevan de Asta, contra D. Antonio Miyar (casado con D. ${ }^{a}$ Rufina Ortega) de treinta y cinco años de edad, natural de Corao en el consejo de Onís de Asturias, y vecino y del comercio de Libros de Madrid. Por suponerle con otros conspirador contra el Gobierno absoluto», en Colección de las Causas más célebres e interesantes [...] del foro español, francés e inglés. Por una Sociedad de Jurisconsultos. Parte española. M., Librería de D. Leocadio López, 1863. Tomo V, pp. 176-382. (En adelante Causas.) 
su mujer, D. a Eugenia Morales, la cual se hallaba en compañía de D. ${ }^{a}$ Esperanza Planes Bardají, esposa de otro revolucionario, D. Florentino Arizcun, y en compañía también de su primo D. Mariano Bardají, joven ibicenco. Marco-Artu no fue habido, pero sí todos sus papeles, y otros se procuró Calomarde por medio de sus agentes. Del examen de estos papeles y por las noticias previas que ya tenía Calomarde resultaba que Marco-Artu, Torrecilla y Olózaga formaban parte de una llamada Junta Superior a la cabeza de las del Reino y en correspondencia con los Generales Mina, Torrijos y demás. Este título y la mención en él de Mina y Torrijos merecen una explicación.

\section{Las Juntas}

La Junta Superior citada se componía de D. Francisco Bringas, propietario; D. F. Bárcenas, del comercio; D. Antonio Enri, ex Coronel secretario de la Inspección de Caballería; D. N. García, ex Oficial de la Secretaría de la Guerra; Marco-Artu; D. N. [Tomás] Polo Catalina, ex Oficial de Secretaría; los Torrecillas, y De Miguel, artillero impuro $^{9}$. La existencia de esta Junta y el nombre de Superior que llevaba parece haber sido idea de Bringas, quien la concebía como un cuerpo independiente, aunque relacionada con los militares emigrados, pues decía que la Revolución la tiene que hacer la Nación y ha de salir de ella ${ }^{10}$. De manera que aunque Bringas daba dinero para la revolución, haciendo en cierta manera de representante de Espoz y Mina en Madrid para asuntos de Hacienda, no se consideraba sometido a la autoridad del General, como tampoco los demás. Marco-Artu era en Madrid el centro de todas las actuaciones, y aunque en su correspondencia abundan la censuras para Bringas y otros, actuaba también con independencia. El pensamiento oficioso de Mina respecto de la Junta se deja adivinar: hay que destruirla, se dice en una carta de Burdeos, 2 marzo $1831^{11}$; y en la misma se aprueba la idea de la formación de una comisión - palabra que en esta época se toma con el mismo valor que la de junta - con sujetos de probada fidelidad. En otra carta, fechada en Valencia 12 marzo 1831, y firmada por Romualdo Solís, se dice con referencia a la Junta de Madrid, a la que llama intrusa, que «debiais des-

9 Causas, V, 219; documento $\mathrm{n} .^{\circ} 1$, que constaba en la orden de Calomarde de 16 de marzo 1831.

10 Causas, t. V, pp. 268-9.

11 Id., t. V, pp. 245-7. 
de luego tratar de hacerla desaparecer de cualquier modo que fuese» ${ }^{12}$. Pero la idea de junta o comisión está en el ambiente: el comisionado de Cuenca, 8 marzo 1831, adelanta para la Junta Suprema Gubernativa los nombres de D. Vicente Cano Manuel, D. Ramón Giraldo, Bardají, el eclesiástico Posada, si es posible, y añade que convendría pensar en Oñate, Frías y algún otro ${ }^{13}$. Estas desavenencias se dan entre los colaboradores o partidarios de Espoz y Mina, ya que éste trata de asegurarse siempre la supremacía. Lo cual no impide que las Juntas y las Comisiones se hayan extendido por todo el país. Un denunciador bastante siniestro, el Alcalde Mayor de Tolox y Monda, D. Antonio María Pacheco, al que se quiso ganar para la conspiración y fingió aceptar, denuncia el 30 de junio de $\mathbf{1 8 3 1}$, pero con referencia a un año antes, que

En todas las capitales de provincia de la Nación existían juntas compuestas de sujetos libres y filantrópicos que tenían comunicación entre sí, y con la provisional del Reino, constituida en Bayona ${ }^{14}$.

Efectivamente se tiene noticia de la existencia de las Juntas de Pamplona, Valencia, Murcia, Málaga, Hellín, Granada, Sevilla, Carmona, Cartagena, Córdoba, Bujalance, Gibraltar, Lisboa, Bayona, Manzanares o de la Mancha, y de las Comisiones de La Coruña, Santiago, Bilbao, Asturias, Salamanca, Ledesma, Valladolid, Zaragoza, Cuenca, Peñas de San Pedro, Badajoz, Alicante, Cartagena (puede ser la junta anteriormente citada), Murcia, Jaén, Manzanares, Granada, Málaga, Valencia, Ciudad Rodrigo, Pamplona, La Roda, Quintanar de la Orden, Belmonte, Sevilla. La conspiración se extiende por todos los puntos de la geografía peninsular.

Pero no todos estos puntos dependen de Espoz y Mina, o no dependen sólo de él. En muchos consta su obediencia a la Junta General de Españoles Emigrados, de Londres. Es decir que había una multiplicidad de dependencias, y una autonomía de hecho bastante grande, y también bastante versátil. De la Junta de Londres no formaba parte Espoz y Mina, ya que estaba integrada por Torrijos, Espinosa, Plasencia, Butrón, Peón, Gurrea, Flórez Estrada, Flores Calderón, Núñez y Palarea, que hacía de secretario perpetuo. No tenía Presidente, sino que se elegía uno para cada sesión ${ }^{15}$. En la práctica, cuando un punto cualquie-

12 Archivo del Ministerio de Justicia, Armario Reservado, leg. 15 (en adelante Arch. Justicia). Conste aquí mi agradecimiento a D. ${ }^{a}$ Ana Galicia López, por las facilidades que me dio para consultar el Archivo.

Causas, t. V, pp. 263.

14 Id., p. 286. Es la versión que se daba para sumarle a la conspiración.

15 Según el delator J. R. (Juan Rumí) (Causas, t. V, p. 355). 
ra del interior de España entabla relaciones con el centro de Londres, inmediatamente acuden los enviados de Mina con promesa de medios económicos y militares; y es imposible negarse, aun con suspicacia, a entrar en relación. Lo mismo ocurre, pero acaso la resistencia és mayor., si el primer contacto se ha establecido con Espoz y Mina.

Conocemos la composición y a veces los orígenes de algunas de estas Juntas. La de Cádiz se componía en 1830 de D. Juan López Ochoa, D. Manuel López Ochoa, D. Damián Bustamante, El P. Fr. José Juan González, el Coronel Rengifo, el Teniente Coronel Sánchez Navarro, los dos últimos en correspondencia con D. Felipe Ribero. Agente era un tal Ballesteros, tuerto. Celebraba las reuniones en casa de D. Carlos Lobé, Cónsul de Holanda ${ }^{16}$. Personajes fundamentales en toda esta historia andaluza son los López Ochoa, especialmente el primero, Juan, antiguo secretario de la Sociedad Patriótica de Sevilla en 1820 y secretario también de la Compañía del Guadalquivir ${ }^{17}$, al que encontraremos en 1834 de agente de la Casa londinense de Pablo Pebrex y Cía., de Warnford-Court ${ }^{18}$. Los Ochoa, pues, son también responsables del establecimiento de la Junta de Córdoba, en el verano de 1829. Se formó en casa de D. Juan Antonio Iniesta, médico, y a ella pertenecía D. Rafael de Lara y Cárdenas, cura de Almonaster la Real, que había sido recomendado por D. Manuel López Ochoa. Formaba parte de ella también D. F. Navajas, poseedor de unas alcabalas en Cádiz, natural o vecino de Pozoblanco. Se enviaban las cartas a D. José M. ${ }^{a}$ Uruburu, en Montemayor ${ }^{19}$.

La Junta de Carmona se formó a propuesta del Coronel Márquez y de D. Gregorio Pascual, y la integraban D. Martín González de Navas, antiguo canónigo de San Isidro en Madrid, D. Manuel Abad, D. Julián López, D. F. Caracuel y otros. Esta Junta tenía muchas relaciones y decía contar incluso con los realistas ${ }^{20}$.

La Junta de Granada, también llamada de Granada y las Alpuja-

Según el delator Santiago Vicente García (Causas, t. V, pp. 311-2).

Cf. Alberto Gil Novales: Las Sociedades Patrióticas, M., Tecnos, 1975, 2 vols. (en adelante: Soc. Patr.), p. 865.

Cf. P. Pebrer: Memorias o Exposiciones entregadas al Gobierno de S. M. C., por los SS. D. Angel Moreno e Hijos, a nombre de la Casa de Comercio de P. Pebrer y Compañia de Warnford-Court, de la Ciudad de Londres. París, Didot, 1834, página 6.

Causas, t. V, pp. 219 y ss. y 314. Cf. la defensa de D. Rafael de Lara y Cárdenas, escrita por D. Joaquín Pérez Seoane, en Causas, t. IV, pp. 205 y ss.

Causas, t. V, p. 333. 
rras, dependiente de la General de Emigrados de Londres, se formó con conocimiento o dirección de D. Juan López Ochoa, que escribía con sobre a D. Carlos Monteagudo ${ }^{21}$. La Junta de Málaga, presidida por el Coronel D. Antonio Bray -secretario, el abogado D. Antonio Fernández del Castillo-; se hallaba en relación con las de Granada y las Alpujarras y Cartagena ${ }^{22}$. La de Sevilla, fundada en 1829 también por Juan López Ochoa, dependía de la General de Emigrados de Londres, y estaba compuesta en su último estado por el P. Fr. Antonio Rabadán, Regente de Estudios del Convento de Agustinos Calzados de Sevilla; D. Juan Antonio Iniesta, médico; D. José Jiménez, Secretario que fue del Gobierno político de Cádiz en 1823; D. Manuel Martínez, Oficial que fue de la Secretaría de la Gobernación de Ultramar; D. Bernardó Márquez, Coronel de caballería impurificado; D. José María Domínguez, Teniente Coronel ilimitado, que al parecer acabó retirándose de la Junta; D. Antonio Valcárcel, que había pertenecido a la Milicia Nacional Voluntaria de Madrid, y era encargado de negocios del Conde del Aguila, D. Manuel de la Huerta, Comisario de Guerra, y D. Santiago Vicente García, antiguo afrancesado, que usaba el nombre de guerra de Francisco Vázquez, y cuyas delaciones van a ser decisivas para la reconstrucción de toda esta trama. De la dirección se encargó D. Bernardo Márquez. Según el delator, esta Junta se hallaba prevenida contra Torrijos, al que se acusaba de temeridad, a lo cual ayudaban las cartas de Marco-Artu en este sentido, y desconfiaba de Mina, a pesar del intento de uno de los Torrecillas de hacerla someter a la autoridad de éste. La conclusión fue decir que los miembros de la Junta sevillana no tienen espíritu de partido ${ }^{23}$.

Para la Junta de Jaén se enviaba la correspondencia a D. Felipe Fernández y luego a D. Pedro García. Lo que en ella dominaba era muchas preguntas y recelos, curiosidad y desconfianza ${ }^{24}$. La última de las juntas andalużas de que tengo algún dato, la de Orjiva y Laugar, muy cerca de Granada camino de las Alpujarras, estaba presidida por el cura párroco D. Andrés Perea de la Roca, según carta de cierto D. Toribio Ramón de Funes a Flores Calderón y Torrijos ${ }^{25}$.

De Cartagena se nos adelanta la convicción de que «allí existe la

Archivo del Ministerio de Justicia, Armario Reservado, leg. Torrijos.

Causas, t. V, pp. 307 y 313. El mismo se firmaba Diego Madueño (id. 312).

Causas, t. V, pp. 286 y 312.

Id., pp. 307-310.

Id., p. 314. 
gran reunión o Logia principal». Dejando por el momento este lenguaje masónico, sobre el cual volveremos, el subdelegado principal de policía de la provincia de Valencia, Fernando José Toledo, a quien pertenecen las palabras transcritas, añade el 21 de mayo de 1831 que habiendo visitado Cartagena en abril, mayo y junio de 1825 pudo comprobar «que el espíritu de la revolución y anarquía tenía allí un firme apoyo y segura guarida». A finales de 1830 parecen seguir a Mina, pero también se hallan en contacto con Torrijos ${ }^{26}$. De la Junta de Hellín formaban parte D. José María Rodríguez, Teniente Coronel retirado, D. Ramón Martínez, Teniente Capitán que fue comandante de la M. N. V. de Almansa en 1822 y 1823, y D. Hipólito Núñez, hacendado ${ }^{27}$. En Peñas de San Pedro (Albacete) se cita al médico D. Genaro Vathet y Miñano ${ }^{28}$. De la Junta de Murcia formaban parte D. Antonio Trigueros, D. Francisco Molina (hermano del Vizconde de Huerta) y D. N. Samaniego, entre otros. Las cartas se dirigían a D. Lorenzo José Ramírez ${ }^{29}$.

La Junta Superior de Alzamiento de la Provincia de Valencia reconoció la autoridad de Mina el 22 de enero de 1831. El Presidente era Julián de Ilarreta, y el vocal secretario Marcelo Venegas ${ }^{30}$. En la Comisión de La Coruña se cita a Azcuénaga y Pantigosa, oficiales del Ejército $^{31}$. El Capitán de artillería impurificado D. Manuel Gerona pasa a dirigir los trabajos de Zaragoza y Barcelona, donde estaba ya en 1826 por cuenta, se dice, de Mina y Torrijos. El que llevó la comisión, supongo que a Zaragoza, fue Perena. Barcelona es difícil, «por haber fusilado a tantos de ellos, mandado a presidio a otros y desterrado a los restantes ${ }^{32}$.

Según las declaraciones de Juan Rumí, otro tránsfuga, hechas el 5 de abril de 1831, la Junta de Gibraltar, formada hacia 1825, estaba presidida por Francisco Diaz Morales, y de ella formaban parte Perena y el coruñés Fernández Pereira. Díaz Morales es el autor de una nota o memoria dirigida al ex-Emperador D. Pedro del Brasil, iniciativa que también tomó la Junta de Lisboa, y en su nombre Francisco Fernández

Causas, t. V, p. 300, y Arch. Justicia, legs. Marco-Artu y Torrijos.

Causas, t. V, p. 303.

Id., pp. 255 y 323.

Id., p. 272.

Arch. Justicia, leg. Marco-Artu.

Causas, t. V, p. 322.

Id., pp. 272-3. Sobre los fusilamientos de liberales en Barcelona, cf. Justo Pastor de Pellico (Rafąel Farga Pellicer): Garibaldi, Historia liberal del siglo XIX, B., Est. Tip. Editorial «La Academia», 1889, 2 vols., t. I, pp. 793-4. 
Golfín. La Junta de Gibraltar se hallaba en correspondencia con la Asamblea de Constitucionales Europeos, de Londres ${ }^{33}$.

\section{Los Constitucionales Europeos}

La Sociedad de Hermanos Constitucionales Europeos había sido fundada por el General napolitano Guglielmo Pepe, como sociedad secreta, en Madrid 1821, a raíz de su llegada a España en abril del mismo año. Según el mismo Pepe dice, los ingleses se negaron a cooperar, mientras que Lafayette se adhirió ${ }^{34}$. Esta Sociedad, por lo que respecta a España, pasó a llamarse Centro Universal de Actividad Patriótica, y representaba en el exilio de Londres el intento de unión de masones, comuneros y carbonarios, según una especie de Constitución publicada en 1826 con el título de "Sistema adoptado para instalación y progresos de la gran fortaleza peninsular de españoles emigrados. Al oriente de Madrid». Por un despacho de Ofalia a González Salmón, Londres 23 febrero 1828, conocemos la identidad entre la Asamblea Constitucional Europea y el Centro General o Universal de Actividades Patrióticas, y también que en 1828 se hallaba integrado por seis españoles refugiados, y otra porción de portugueses, americanos insurgentes [sic], italianos, franceses e ingleses hasta el número de 21 . El delator Juan Rumí descubrió que Díaz Morales, a cuya Junta de Gibraltar acusa de despreciable e inútil, estaba en relación con la Asamblea de Constitucionales Europeos, «compuesta de extranjeros y españoles entre ellos Flores Estrada, Romero Alpuente, Beltrán de Lis, D. Domingo de la Vega, y un tal César Conti que firmaba como secretario e intérprete». El mismo entra en contacto con la Asamblea, a fin de poderla delatar mejor. Pero lo que Rumí no sabía es que el secretario Conti era otro agente de Ofalia, un tanto fanfarrón, antiguo revolucionario ya en enero de 1831 al servicio del Cónsul de España en Bayona, y después agente de Ofalia: entre los datos que le comunica, los hay sobre el Centro de Actividades Patrióticas, unión efectivamente de comuneros, masones y carbonarios, pero iniciativa de los primeros. Añade también que últimamente ha sido trasladado el Centro a París, pero esto último debe de ser posterior al descubrimiento de la conspiración de Marco-Artu, como sabemos en

33 Causas, t. V, pp. 348 y 355.

34 Cf. Guglielmo Pepe: Memorie del generale intorno alla sua vita e ai recenti casi d'Italia scritta da lui medesimo, Parigi, Baudry, 1847, t. II, pp. 147, 160 y 163. Pepe había llegado a Barcelona el 20 de abril de 1821. Cf. Guillermo Pepe: Memoria relativa a los sucesos políticos y militares de Nápoles en los años de 1820 y 1821, M., Imp. de D. Miguel de Burgos, 1822, p. 149. 
marzo de $1831^{35}$. Es posible que los datos del despacho de Ofalia citado procedan de Conti, aunque añade que el instalador es el catalán A. Baiges, que fue guardia de corps, y que con nombre supuesto ha estado en Cataluña durante las últimas turbulencias, es decir, en la guerra de los Agraviados.

Esta Sociedad fue protagonista de varias acciones en favor del restablecimiento del liberalismo español. Buscando apoyos internacionales y dinero, se dirigió al Duque de Sussex por medio de Sir Robert Wilson ${ }^{36}$, pero el Duque se negó. Después la Sociedad dirigió también una nota a D. Pedro del Brasil, y si Juan Rumí está en lo cierto, D. Pedro estaría muy atento a los planes de los Constitucionales Europeos, de los cuales no quería apartarse. Juan Rumí añade que al infiltrarse en ellos en la segunda mitad de 1827 , se encontró con que no se reunía la Asamblea, por estar casi todos sus miembros en el continente. Pero le nombraron secretario de la Sección de España, de la que acabó retirándose porque la reunión, siempre según él, no gozaba de crédito. Antes que él se retiró Flórez Estrada ${ }^{37}$.

\section{Don Pedro del Brasil}

La repetida mención de $\mathrm{D}$. Pedro del Brasil plantea uno de los temas fundamentales del liberalismo español en la década, de tanta importancia como la revolución europea de 1830 , sobre la que en definitiva incide. A raíz de la doble catástrofe del liberalismo peninsular en 1823, los liberales tanto españoles como portugueses escucharon la lección de quien achacaba en parte dicha catástrofe a la falta de entendimiento entre ellos ${ }^{38}$. Las circunstancias que llevan a la crisis constitucional portuguesa van a hacer posible el surgimiento de un pensamiento iberista, centrado en torno a Don Pedro, a quien se ofrece el trono hispano-portugués. Los contactos van a tener varios aspectos y larga duración. El punto de unión, naturalmente, es la oposición a D. Miguel y

35 Cf. Aviso a los incautos sobre los ridículos y vanos proyectos del llamado Centro Universal de Actividad Patriotica establecido en Londres (foll. en BN Madrid, VE/ca. 742-13), Escritos del Conde de Ofalia, Bilbao, Sociedad Anónima La Propaganda, 1894, pp. 608-10, y AHN, Estado, leg. 6284-164 (Conti). Cf. Soc. Patr., pp. 801-2.

Es lástima que el reciente libro de Michael Glover: $A$ very slippery fellow. The life of Sir Robert Wilson 1777-1849, Oxford Univ. Press, 1978, no estudie estos aspectos.

Por ejemplo, el mismo Pepe. Cf. Soc. Patr., p. 912. 
a su paralelo español Fernando VII -cuando el problema se plantea faltan todavía muchos años para que aparezca la crisis carlista-. D. Pedro, para su acción puramente portuguesa, busca un empréstito con casas bancarias inglesas, y los liberales españoles, faltos también de dinero, buscan acercarse a la misma fuente. Sin olvidar nunca este tema, acaso los primeros en perseguir en la figura de D. Pedro la unión ibérica fueron los militares españoles que después de 1823 se hallaban en los depósitos portugueses, concretamente en el de Peniche. Según los recuerdos, demasiado vagos, de Eusebio Asquerino, relativos a su padre que era Comandante del depósito, y Coronel antiguo ayudante de campo de Espoz y Mina en Cataluña, él y Carlos Pemán, Pingarrón, José Aramburu, Padilla, Alcaraz y Epifanio Mancha (padre de la Teresa de Espronceda) instrumentaron una conjuración de unión ibérica contra D. Miguel. Descubiertos, fueron encerrados en un navío, y sólo les salvó de la muerte la aparición del general Saldanha y del propio D. Pedro. Después algunos se inscribieron en el famoso Regimiento de Cazadores de Oporto, luchando, según dice Eusebio Asquerino con énfasis, «a las órdenes de D. Pedro, que era ardiente partidario de la unión de las dos naciones peninsulares ${ }^{39}$.

Joao VI murió en marzo de 1826. Un mes después D. Pedro otorgaba a Portugal una nueva Constitución. Este fue el momento en que recibió las notas o exposiciones de la Junta de Gibraltar (Díaz Morales), de la de Lisboa (Fernández Golfín), de los Constitucionales Europeos y de Espoz y Mina. Es el momento en que se señala la presencia en Lisboa de Florentino Arizcun ${ }^{40}$, pero también el de la intervención absolutista española en Portugal, 1826-1827, que acaudilló el General Longa ${ }^{41}$, y la llegada de muchos liberales españoles, alguno de los cuales, como Juan Romero Alpuente, fue expulsado del país ${ }^{42}$. La respuesta de D. Pedro, dada por medio del Cónsul brasileño en Gibraltar -al que se describe como íntimo de los comisionados de la Junta de Londres en Gibraltar, llamados Francisco de Borja Pardío y Manuel

39 Combino los datos que da Eusebio Asquerino en sus artículos «España y Portugal» y «La América», en La América, M., 28 junio 1882 y 28 diciembre 1883. La frase transcrita, en el segundo art., p. 9. Cf. también Historia de una idea. España y Portugal, M., Fortanet, 1869, en donde se habla de Díaz Morales, Flórez Estrada y Juan Rumí, en relación con Don Pedro (pp. 10-11). Del último dice equivocadamente que murió en Málaga con Torrijos.

Causas, t. V, p. 310.

41 Cf. Luis Fernández Martín, S. J.: El general don Francisco de Longa y la intervención española en Portugal, 1826-27, Bilbao, 1954.

42 Cf. AHN, Estado, leg. 5447-32, y mi próxima edición de los escritos de Romero Alpuente. 
García del Barrio ${ }^{43}$ - , fue vaga y diplomática, pero sin rechazar ninguna propuesta, sólo sometiendo las futuras decisiones a las supremas virtudes de moralidad y justicia. Lo cual era una manera de ganar tiempo. No obstante, al parecer Mina confiaba en que se iba a lograr el empréstito gracias sobre todo al nombre de D. Pedro. En efecto, Juan Rumí afirma que por medio de Gibraltar D. Pedro habría facilitado fondos, pero también se apresura a añadir que acaso se ha abusado de su nombre ${ }^{44}$. Pero como en todas partes, los españoles en Portugal, aparte los serviles, se hallan divididos entre partidarios de Torrijos y partidarios de Mina $^{45}$. La realidad, no obstante, impone la cooperación. Decididos partidarios de la unión ibérica, como antídoto contra D. Miguel, son en Portugal el General Saldanha, el Arzobispo de Elvas, el General Jorge Avilé, el médico Abrantes, el Conde de San Payo, etc. En 1827 se celebra una entrevista entre Juan Rumí, Saldanha, Abrantes, Espoz y Mina y Torrijos, en la que convencidos de la aceptación de D. Pedro, Saldanha y Abrantes ofrecen un millón de duros reunido por el comercio de Lisboa, pero el triunfo de los realistas en Oporto impide llevar a cabo la operación ${ }^{46}$.

La Junta General de Españoles Emigrados en Londres decide enviar un comisionado directamente a Río de Janeiro, y piensa en un principio en Juan Rumí, naturalmente desconociendo su condición de agente doble. Este declina, y se encargan de la misión dos coroneles portugueses ${ }^{47}$. La Junta adopta también otra importante decisión: la de buscar el apoyo de los nuevos países hispanoamericanos, ofreciendo a cambio el reconocimiento de la independencia. Torrijos, Flores Calderón y Flórez Estrada son los encargados de la negociación. Algunos prohombres respondieron favorablemente, como Rocafuerte, Hurtado, La Madrid y Gorostiza; éste convocó a los otros tres, a fin de actuar mancomunadamente, pero es el caso que en febrero de 1830 todavía no se había resuelto nada. También se hicieron gestiones con RivaAgüero y con San Martín, y por lo menos el primero en 1829 prometió ayuda, y aún llegó a darla si hemos de creer a una carta escrita proba-

43 Junto a ellos, en la Junta de Gibraltar, se cita a D. Antonio Lorenzo Gaitán, D. Juan Antonio Escalante, D. Antonio López Ochoa y D. Salvador San Juan (Luis Cambronero: Torrijos, Málaga, Sociedad Económica, 1931, p. 156). Francisco de Borja Pardío, lo mismo que Fernández Golfín, fueron fusilados con Torrijos el 11 diciembre 1831 (Cambronero, op. cit., 221).

Causas, t. V, pp. 347-9. 
blemente por Ignacio López Pinto y dirigida desde París, 28 septiembre 1831, a Torrijos y Flores Calderón ${ }^{48}$. En la misma carta se dice que el empréstito concluido por D. Pedro es poco ventajoso. Unos meses antes, discutiendo en París una urgente petición de dinero hecha por Torrijos y Flores Calderón desde Gibraltar, 13 enero 1831, se dice que el millón de libras esterlinas de D. Pedro no se negocia en París, a pesar de lo cual la fácil asociación entre los conceptos de empréstito y.D. Pedro no se borra de las mentes españolas ${ }^{49}$. También se busca en Londres la firma de los todavía llamados insurgentes americanos, como garantía para un posible empréstito, pero según Juan Rumí se trata de firmas desacreditadas ${ }^{50}$.

\section{La Masonería}

El problema de las instituciones y organizaciones revolucionarias está íntimamente unido al de la unidad, o falta de unidad, de los liberales, y en última instancia a su historia personal e ideología dominante. Ya se ha mencionado uno de los intentos de unidad, el Centro de Actividades Patrióticas de Londres. Los papeles relativos a la conspiración de Marco-Artu hacen frecuentes referencias a las «dos sociedades» ${ }^{51}$, es decir, a las de masones y comuneros, con poca simpatía por estos últimos. Los trabajos masónicos son muy antiguos. El delator V. R. revela que en 1825 Mariano y Pedro Riera intentaron introducirle en una logia en Barcelona ${ }^{52}$. Años después, hacia 1830 ó 1831, en plena conspiración de Marco-Artu, se habla de los trabajos masónicos de Barcelona como pieza de peso en el engranaje general ${ }^{53}$. El mismo V. R. declaraba que hacia 1827 D. Antonio Garrigó, Oficial impurificado de caballería,

48 Según Santiago Vicente García, Causas, t. V, pp. 351-2, y BN, papeles Lafayette (que son más bien de Ignacio López Pinto).

Cf. BN, papeles Lafayette.

50 Causas, t. V, p. 351. La cuestión americana llevó a algunos partidarios de Torrijos a ultrajar a Canga Argüelles, con motivo de la publicación por éste del folleto archirreaccionario Breve respuesta a la representación de los comerciantes de Londres y a varios artículos depresivos del honor del Monarca español, insertos en el periódico «El Times», sobre el reconocimiento de la independencia de las Américas Españolas, Londres, Marcelino Calero, 1829. Cf. Francisco de Cea Bermúdez a Manuel González Salmón, Londres, 8 de enero 1831, en AHN, Estado, leg. 5518.

51 Por ejemplo, en Valencia (Causas, t. V, p. 260).

52 Causas, t. V, p. 293.

53 Id., p. 268. 
le quiso inscribir en la masonería valenciana: le llevó a una corporación, toda compuesta de oficiales impurificados, cuyo jefe era D. José Díaz, Capitán ilimitado de infantería. En los días siguientes, haciendo discretamente averiguaciones, aunque no pudo saberlo todo, se enteró de la existencia de la corporación de Cullera, que pertenece a la de Cartagena, y todo en definitiva dependía de Cádiz. Logias o corporaciones existían también en Castellón, Denia y Murcia ${ }^{54}$.

Siguiendo el criterio indicado más arriba, Espoz y Mina hacia 1830 organiza o deja organizar su Junta Central Directiva, a la que creo diferente de todos los organismos hasta ahora citados, y que se compone de los ciudadanos Caleb, Malec, Zadi, Constans, Calcas, Eurialo y Ascanio, los cuales en otro tiempo y con otros nombres habían formado parte del S. $\cdot$ G. $\cdot$.C. $\cdot$.G. $\cdot$. del O. $\cdot$.M. $\cdot$. (Supremo Gran Capitulo General del Oriente Masónico). En este momento se establece un muy curioso razonamiento. A los individuos de la Junta no se les ocultan los peligros que conlleva la adopción de métodos masónicos de actuar, pero esto les viene impuesto desde las provincias, donde se han adoptado para mejor garantizar el secreto de sus operaciones. El peligro proviene de la experiencia pasada del Trienio liberal: «la escandalosa publicidad de cuanto se obraba en el Oriente masónico», por la intrusión en el mismo «de sujetos innoblemente ambiciosos, que careciendo de talentos, méritos, servicios y virtudes, que los elevasen a puestos y empleos que eran incapaces de desempeñarı, buscaban su apoyo en la institución masónica, es decir, en definitiva, se trataba del descubrimiento de un problema de política general, el del oportunismo y la ambición en los cuerpos políticos. La reflexión continúa con la rivalidad que los mismos sujetos lograron introducir entre la masonería «y otra sociedad de patriotismo puro y probado en la generalidad de sus individuos, pero cuya creación tuvo su origen en la dañada intención por parte de $\mathrm{m} . \cdot$ espurios de establecer esta misma rivalidad, y dividir por tales medios a los amantes de la libertad»-alusión, me parece a mí, a la creación de la Comunería en 1821, y a la presencia de Regato, es decir, de un agente provocador entre sus miembros fundadores-. La apostasía, en fin, y el perjurio políticos convertidos en norma, «y sobre todo la horrenda felonía de haber puesto en manos de nuestros cobardes y encarnizados enemigos el libro de oro o catálogo general de cuantos individuos componían el orden» (masónico). Esto les lleva a una reflexión final sobre las sociedades secretas, «convenientes, útiles y aun necesarias para de-

54 Id., pp. 294-6. 
rrocar un despotismo opresor", pero «perjudiciales y ominosas después de establecida la libertad» ${ }^{55}$.

Llamado el antiguo inquisidor D. Raimundo Ettenhard y Salinas, representante que fue de la Suprema Inquisición en la Junta napoleónica de Bayona, 1808, y ahora vicepresidente de la Junta reservada de Estado, a dar su opinión sobre quiénes se escondían en los nombres de Caleb, Malec, etc., se extendió en consideraciones sobre que los masones de 1820 usaban nombres griegos y romanos, mientras que los de 1831 parecen hebreos. De hecho sólo acertó a desentrañar tres nombres: $\mathrm{Ca}$ leb según él era José Tellería, grado 17 dignidad de secretario en el Taller de la Logia Luz; Malec es anagrama de Lamec, nombre simbólico del comerciante D. Mariano Juara, mientras Zadi es anagrama de Díaz ${ }^{56}$.

Domina por tanto el imperativo de unión, pero las cosas no son fáciles. Una carta de Ambrosia Torrecillas, Valencia, 14 diciembre 1830, habla de un proyecto de unión, dificultado porque los comuneros quieren formar su propia Junta soberana. Los comuneros o lo que sea, a los que en otro momento llama Torrijeños, están representados por un tal Orronaz (u Oronaz), amigo de (López) Ochoa, quien trata de imponer sus condiciones para la unión. Pero, siempre según esta misma carta, los comuneros han caído en gran desprestigio debido a sus ofrecimientos de empleo o de mejora de categoría por todas partes ${ }^{57}$. Ambrosia Naudín -ignoro si es la misma- escribe también desde Valencia: esta gente - denominación con la cual parece aludirse a los comuneros- se uniría a la insurrección, «pues que están todos con la mayor impaciencia esperando la señal del rompimiento», pero pide urgentemente instrucciones, pues «acabo de saber tratan de adelantarse, con el objeto de arrastrar también los nuestros si les fuese posible y lucirse de este modo; pero puedo aseguraros que en tal caso podrían llevarse algunos paisanos, pero toda la caballería e infantería con que contamos está resuelta a no seguir otro movimiento que el nuestro y contrariar el de ellos $s i$ fuese necesario». Termina hablando del rumor de un próximo desembarco de Torrijos, del que la policía ya está enterada: acaso es esto lo que tiene soliviantados a los comuneros, puesto que se teme un desmo-

55 Id., pp. 235-7, y Arch. Justicia, leg. Marco-Artu, carpeta 10: falta aquí el nombre de Constans.

56 Causas, t. V, pp. 370-2. Nada de lo que se dice en el texto respecto de la masonería de la época se encuentra en Josẻ A. Ferrer Benimeli: Masonería española contemporánea, M., Siglo XXI, 1980, I.

57 Arch. Justicia, leg. Marco-Artu, carpeta 5. Cf. Causas, t. V, pp. 245 y 246. 
ronamiento general si no se apresuran. La pregunta final es qué debe hacer si efectivamente se presentase Torrijos, «y también con éstos, si quisiesen adelantar el rompimiento aunque aquél no se presente ${ }^{58}$. La respuesta fue que se le ayude, pero no se le obedezca ${ }^{59}$. Otra carta de la misma procedencia, aunque no firmada, Valencia 12 febrero 1831, informa de la presencia de D. Andrés Bazán, jefe de Estado Mayor que fue de Riego en Las Cabezas y de Torrijos y Espinosa en Navarra, académico por Arquitectura en la Academia de San Carlos, y pretendiente a ingresar en la de San Fernando, en Madrid; al cual se le han presentado estas gentes, «ofreciéndole si quería ponerse a su cabeza hacer la unión», pero se le dice que conteste que no pueden reconocer a otro más que a Mina, que no pueden obedecer otras órdenes que las vuestras (es decir, de Marco-Artu), no más asalto a los empleos, ni más trabajos que los patrióticos, etc. «No sé qué contestarán aunque me presumo que nada pues el articulillo empleos es muy dulce para ellos y muy agrio el perder la esperanza de apropiárselos ${ }^{60}$.

El intento valenciano de unidad no terminó con esto. En la época misma del descubrimiento de la conspiración de Marco-Artu, del lado comunero la negociación la lleva Fernando Rubín de Celis, definido como uno de los mejores oficiales del Ejército ${ }^{61}$, y hermano del famoso Miguel R. de C., tan importante en la historia colonial española de finales del siglo XVIII. Nos informa de los tratos una carta de Rufino Lóriga, firmada Agis, y otra de Romualdo Solís. La primera, Valencia 1 marzo 1831, habla de las entrevistas con Agis y con Rubín, y de que se van a presentar las bases «que nos tenéis prevenidas». A la parte contraria no le toca más que aceptar, pero de todos modos la unión no se hará hasta que la apruebe el principal. La carta de Solís, Valencia 12 marzo 1831 , empieza hablando de la indignación de los $\mathrm{h} . \bullet$ porque esos conjurados hayan entablado relaciones con éstos, es decir, los de Madrid con los de Valencia (a esta carta pertenece la frase, ya citada, de que hay que hacer desaparecer la intrusa Junta). «Tamaños procederes acaban de descubrir sus ideas y manifiestan de un modo demasiado patente cuáles han sido, son y serán sus miras». Como predisposición a la unión no está mal, pero poco después añade: «también creo que si el pronunciamiento no distase tan poco les deshariamos completamente»,

58 Id. Subrayado mío. Aunque es una carta de Ambrosia Naudín, al final firma «Agis», nombre de guerra del verdadero autor.

59 Causas, t. V, p. 264.

60 Arch. Justicia, Marco-Artu, carpeta 5. Subrayado mío.

61 Carta de Burdeos, 2 marzo 1831 (Causas, t. V, p. 245). 
pero como está tan cerca no hay más remedio que orillar las rivalidades y avistarse de nuevo con Rubín de Celis, y forzarle a dar una contestación terminante. Rubín de Celis por fin contestó que la Junta (la de estas gentes) había acordado «se nombre una persona de cada Sociedad para tratar y transigir sobre la unión sin perjuicio de que el Centro resuelva». La carta termina con cierta rabia: "veremos si nos vuelven a engañar» ${ }^{62}$.

Los comuneros tienen más poder del que normalmente les hubiésemos otorgado. Por lo menos en algunas localidades. Inmediatamente después del descubrimiento de lo de Marco-Artu, alguien que firma P. A. denuncia desde Albacete, 10 abril 1831, que en la ciudad se han espontaneado 52, pero que son muchos más. Son dueños de la plaza de toros nueva, en la que celebran sus reuniones con toda impunidad. Hacen lo que quieren, pues dominan Albacete al dominar al Corregidor D. Felipe Sandoval y Chaves, vejete a su vez protegido por su suegro (sic) D. Agustín Riquelme, Oidor de la Chancillería de Granada. Pero al mandar Calomarde esta delación al Gobernador de la Sala, Aranjuez 5 abril 1831 (sic), aclara que en la misma se llama comuneros a los que lo fueron ${ }^{63}$.

No termina aquí la nómina de instituciones revolucionarias. Aún se habla de una Junta revolucionaria de Madrid, en 1830, al parecer diferente de todas las anteriores, y de la que forman parte D. Ignacio y D. Calixto González y D. Manuel Vita, militares los tres,'siendo el secretario D. Francisco Rodríguez de la Vega.

Esta Junta está en relación con Sevilla, por medio de Santiago,Vicente García (es decir, el eficaz delator de muchas tramas); con Manzanares, por medio de D. F. López Torrecilla, y con Valencia, por medio de D. José Osca. El delator es nada menos que José Manuel Regato, quien en avisos del 26 y 27 septiembre 1830 comunica la desaparición de Rodríguez de la Vega. No obstante, parece que se acusa a Regato de haber dado el aviso tarde, dando tiempo así a que el revolucionario se escape ${ }^{64}$.

El cual parecer haber sido un extraordinario urdidor de tramas: agente de negocios, de muy pequeña estatura — por lo que se le llamaba

62 Arch. Justicia, Marco-Artu, carpeta 5. Subrayado mio.

63 Causas, t. V, pp. 292-3.

64 Causas, t. V, p. 367. Regato sigue siendo el centro de una tupida red de espías, pero Calomarde no lo ve con buenos ojos. Cf. Claude Morange: «José Manuel Regato», Bulletin Hispanique, 3-4, 1977, pp. 481-535. 
Veguita-, pero muy ágil y muy bien relacionado en la Corte. En relación con Marco-Artu y con Antonio Martín, llamado el Empecinado, por ser hermano del célebre guerrillero: con ellos se reunía en la pastelería de Zeferino, calle del León. En relación también con (López) Ochoa y con Bringas, a quien comunica que el General, es decir, Mina, no aprueba las Juntas. Pero alguien natural de Bilbao, que no sé si será el mismo Marco-Artu, se queja mucho de él, porque dice que no vale para dirigir el negocio, porque se ha puesto en relación directa con Bringas, y porque ha querido desacreditarle diciendo que está vendido a Regato (sic). Sabemos que en noviembre de 1830, no antes, Rodríguez de la Vega salió de Madrid, y que el 28 de diciembre se embarcó en Cádiz para Francia ${ }^{65}$. El 15 de junio de 1831 el agente conocido por «el de las $101 / 2 »$ dice que según se cree ha llegado a Burdeos, pero que Mina le recibirá mal, lo mismo que a Malcuarto (Marco-Artu). Un mes después comunica que Mina no se fía de él, porque se le atribuye el descubrimiento de la conspiración de Marco-Artu ${ }^{66}$, lo cual era inexacto. Pero comprobamos, con sorpresa, que también Veguita era confidente de la policía ${ }^{67}$.

\section{Las Cadenas}

Además de las Juntas y de estos personajes extraordinarios, se cita también vagamente la existencia en el interior de otras asociaciones clandestinas, como la llamada la Cadena. Las revelaciones del Capitán indefinido V. R. sobre las relaciones de Espoz y Mina en la zona valenciana hasta cerca de Madrid y Granada manifestaron la existencia de "otra reunión que se llamaba la Cadena», y que al parecer recibía órdenes de Cartagena, y sus ramificaciones llegaban hasta Granada. La organización era muy simple: se ingresaba en ella mediante pago de una cantidad, según los posibles de cada uno; y después se abonaba un duro mensual, aunque en el caso de algunos que no podían pagar, no solamente no se les exigía, sino que se les socorría. Tenían nombrado un tesorero, y al parecer también de entre ellos, general, intendente y jefes del Ejército. Sus jefes eran Ochoa, Subteniente ilimitado, y Aguaguiri, Teniente. En Valencia había como unos cien en la Cadena ${ }^{68}$.

65 Causas, t. V, pp. 309-10, 366, 246, 261, 269-273.

66 Arch. Justicia, papeles entregados por Mellado.

67 Carta de Regato, M., 27 septiembre 1830, en AHN, Estado, leg. 3060.

68 Declaraciones del 14 y 22 de mayo 1831, en Causas, t. V, pp. 296-300. 
También Santiago Vicente García menciona la existencia en Sevilla de muchas Cadenas, compuestas de sargentos y soldados retirados, ex milicianos nacionales de Sevilla y de Madrid residentes en Sevilla, paisanos y forasteros ${ }^{69}$. Es decir, desde el punto de vista militar lo característico parece ser que el grado más alto era el de teniente, pero abundaban más los sargentos y suboficiales. Entre los paisanos, algún comerciante y otros sin profesión declarada.

Incidentalmente se cita además alguna otra sociedad secreta, como los Federados Hijos de Riego, de Almansa, en la que P. R. S. fue admitido en noviembre de 1822 , y que después celebraba las reuniones en su casa, que era la posada ${ }^{70}$; los batallones de patriotas forzosamente también clandestinos, como el de Hellín, adonde deben acudir los comprometidos de Albacete, Montealegre, Alpera y algunos de Almansa, o el de Elda. Se habla también de Cartagena y de Elche, y desde Alicante a Valencia no se espera para el estalle más que el desembarco en sus costas de 2 ó 3.000 hombres $^{71}$.

\section{Lafayette}

No faltan tampoco las relaciones con asociaciones extranjeras, aunque a veces las noticias son vagas y un tanto quiméricas. Nos sorprende leer que la Sociedad Aide-toi, le Ciel t'aidera ${ }^{72}$ ha publicado que ha dado a los patriotas españoles 600.000 francos, pero que de ellos Mina no ha recibido ni un cuarto ${ }^{73}$. Es posible — no hago más que una conjetura - que parte de la ayuda de Lafayette se canalizase a través de

Id., del 14 de mayo 1831, Causas, t. V, p. 329. Me parece que las Cadenas se basaban en la técnica del triángulo. Por lo menos así trabajaba en 1831 la logia de Madrid, según lo que el agente de las 10 y media sonsacó a Mellado (Arch. Justicia).

Declaración del 15 junio 1831, Causas, t. V, pp. 305-6. De los carbonarios de Cádiz habla Calomarde en carta a Regato, M., 15 marzo 1830. Eran D. Angel de Ferrara, presidente; D. Guillermo Cortelo y D. Juan Aréjula, ex-masones. Datos del Agente n. ${ }^{\circ}$, que debe de ser D. José Pérez Santa Maria, quien en la misma fecha es destinado a La Coruña.

Causas, t. V, p. 303.

Sobre esta sociedad, cf. A. Galante Garrone: Filippo Buonarrotti e i rivoluzionari dell'Ottocento (1828-1837), Turín, 1972', Einaudi, pp. 66, 112 y sobre todo 211.

Causas, t. V, p. 273, y Galante Garrone, op. cit., p. 177. Misley mantuvo siempre gran relación con España, en donde murió en 1865. Cf. Salvador Savall i Creus: Giovanni Enrico Misley i la Navegació del'Ebre, separata sin datos bibliográficos; Gabriel Perreux: Au temps des sociétés secrètes. La propagande republicaine au début de la Monarchie de Juillet (1830-1835), París 1931, no menciona ninguna Sociedad de Propagandistas. 
esta sociedad. Terreno más seguro pisamos, a pesar del nombre extraño, cuando sabemos que la Sociedad de Propagandistas se halla en relación con Olózaga, al que le promete ayuda francesa en cuanto se viesen trabajos fundamentales en España, o se pronunciase una plaza o una provincia. Afortunadamente se dice quiénes son estos propagandistas: Lafayet, Barrot (sic) y Moquein. La identificación de los dos primeros no ofrece duda, y el tercero creo que es una falsa lectura por Mauguin, el del Comité de su nombre, tan ligado a Lafayette, Fabvier, Lepelletier y Misley, y en definitiva a la famosa expedición de Saboya de 1831. Juan Rumí declaraba que Lafayette estaba en contacto con los revolucionarios españoles desde 1827 , y tal vez antes, y que había prometido auxilio tanto económico como militar a la revolución española $^{74}$; pero conocemos por su carta al Presidente Monroe de los Estados Unidos la profunda impresión que le produjo la ejecución de Riego en $1823^{75}$.

Los papeles Lafayette de la BN de Madrid demuestran el interés sostenido del General por las consecuencias humanas de la derrota liberal en 1823, en relación muy especialmente con Torrijos (listas de capitulados en Cartagena y Alicante, para poder reclamar subsidios negados hasta entonces por el Gobierno francés), pero también comprueban su interés cauteloso, no exento de generosidad, por las nuevas aventuras. Llama la atención la relación con el Coronel Ignacio López Pinto, que se remonta que yo sepa a 1829, cuando éste vivía en $45 \mathrm{Up}$ per Seymour Street, Euston square, Londres. Ya en 1829 aparece López Pinto íntimamente asociado a las negociaciones de Torrijos con Lafayette, pero es al año siguiente cuando las cosas se precipitan. Torrijos le escribe a Lafayette, Londres 18 mayo 1830, que López Pinto va a pasar (a Francia) sólo para hablarle. Muy importante debía de ser la misión cuando, alegando razones de salud, López Pinto se finge inglés, y con el nombre de Mr. Edward Pictor y un pasaporte dado por el Ministro de los Países Bajos, parte para Ostende el 22 de mayo de 1830. El 27 de mayo, desde el hotel de Orléans, Pictor presenta sus respetos al General, en los que le recuerda los asuntos de Cartagena y Alicante. Lafayette contesta al día siguiente en inglés, indicando que le recibirá en La Grange. El 6 de junio le manda a su hijo, y un auxilio de 1.000 frs. Pero

74 Causas, t. V, p. 350.

75 Lafayette: Mémoires, correspondance et manuscrits, París-Londres, Fournier Ainé, Sander and Otley, 1837-38, t. VI, p. 161. En 1825 Lafayette visitó Nueva Orleáns, donde fue saludado por algunos proscritos españoles, como Campe y Cristóbal de Armas: se habló de Riego y de libertad, etc. (Papeles Lafayette de BN, Madrid). 
el 14 de junio Pictor fue arrestado e identificado, y después de cuatro días de souffrance devuelto a Inglaterra, vía Calais. El 30 de junio, ya desde Londres, agradece su generosidad y menciona expresamente los 5.000 frs. entregados a su amigo para la revolución. La nota siguiente es del 4 de agosto: felicitación por el triunfo de la revolución en Francia, y petición de permiso para cruzar de nuevo el canal. Fechadas a 5 de agosto' de 1830 hay una serie de preguntas sobre los medios morales y materiales para la acción. Y del 6 es la proclama: «Españoles, unión, libertad, llegó el momento». Unos días después, el 17 agosto ${ }^{76}$, Lafayette se alegra de la llegada a París de su amigo López Pinto, con el que va a mantener intensa relación en los próximos meses.

Creo que todos estos viajes de López Pinto, tan llenos de aventura, obedecen tan sólo a una cosa: la necesidad de conseguir dinero, no solamente por los subsidios derivados de las capitulaciones, o por el derecho de los refugiados españoles a recibirlos, ya que sin derecho los habían disfrutado los afrancesados o napoleonistas (sic); sino, sobre todo, la necesidad de conseguir un empréstito, en el que el nombre de Lafayette se asocia con el del banquero Calvo, quien es nombrado agente de Torrijos en Francia: 200.000 francos, según carta de López Pinto de 11 de octubre de 1830 , de los cuales 25.000 correspondían a Mina «según vuestros deseos» - respuesta de Lafayette, sin firma y sin fecha-, pero no se le dieron porque al llegar a Bayona ya estaban distribuidos, lo que le ha contrariado, porque en sus instrucciones lo había claramente dispuesto. Mendizábal había formado en París un Comité Espagnol, compuesto de franceses, para canalizar la ayuda económica. A él pertenecía M. Chevallon, de la Sociedad Aide-toi, le Ciel t'aidera, quien debió haber entregado a Mina los 25.000 francos, pero no lo hizo, ignoro el porqué.

Aunque Lafayette, en sus cartas a Mina de 12 y 24 octubre 1830, le dice que Torrijos le tiene en gran estima ${ }^{77}$, la realidad es que la expedición de Vera se realiza no sólo en medio de las eternas rivalidades personales, sino bajo la impresión de que el capital, tan arduamente conseguido, se ha volatilizado, por lo menos en parte. Así no es extraño encontrar en los papeles de la BN de Madrid una carta de unos oficiales españoles, que en octubre de 1830 han dejado Inglaterra para trasladarse a Bayona, y se han encontrado en la miseria, a no ser por dos francos diarios que les daba D. Vicente Bertrán de Lis, aunque en calidad de reintegro. Imagen que contrasta fuertemente con la del asustado Cón-

76 No consta el año, pero lo pide el sentido.

77 Cf. Núñez de Arenas, op. cit. én n. 1, 275n y 255n. 
sul español en Burdeos, que comunica a su Gobierno el 18 de agosto de 1830 que por las calles de Burdeos han pasado españoles cantando canciones del tiempo constitucional. Pero también añade que uno de ellos tuvo la desvergüenza de ir a pedir dinero a un comerciante ${ }^{78}$.

La expedición de Vera tuvo lugar en octubre de 1830, y en ella no obstante los comités, la intervención de Mendizábal, etc., las disensiones llegaron al máximo. Murió, entre otros, el famoso Joaquín de Pablo, Chapalangarra. Pero la revolución siguió su curso, incluso en esta frontera de los Pirineos. Cuando Torrijos también fracasó en Málaga, su mujer acudió a Lafayette para tratar de salvarle la vida; en cuanto a Ignacio López Pinto siguió en la amistad, invitado en 1832 a la boda de Matilde Lafayette, y doliéndose poco después de la muerte del Teniente General Lamarque. Los españoles estaban agradecidos a Lafayette. Torrijos, desde Gibraltar 21 marzo 1831, le había escrito una carta invitándole a ponerse a la cabeza de los asuntos de Francia, y recordándole el interés de Francia en el triunfo de la revolución española ${ }^{79}$.

Parecen bastante quiméricas las noticias del agente Conti, enviadas desde Bayona el 7 de febrero de 1831 sobre la formación de una división en Francia, de la que se excluye a los realistas y a los que participaron en la expedición de Angulema, y cuyo jefe será Fabvier. Igualmente vago resulta el dicho atribuido a Soult, de que piensa visitar su antigua residencia en Sevilla (se entiende a la cabeza de un ejército) ${ }_{1} Y$ aún más quimérico, aunque yo no diré que no sea posible, el envío por los revolucionarios españoles de una misión a O'Connell, para formar, de acuerdo con los revolucionarios franceses, un cuerpo de veteranos irlandeses, y llevarlos a Terceira, a la sombra protectora de D. Pedro del Brasil, y de allí a Portugal ${ }^{80}$. Una Weltpolitik en suma.

Tampoco Italia estaba ausente. Juan Rumí dice haberse introducido en una Junta de Revolucionarios Italianos, que funcionaba en Londres, 1827, y que mantenía correspondencia con toda Italia, Nápoles y Cerdeña, Estados Pontificios, y con los italianos de Alemania por vía de Malta. El corresponsal era el Conde de Bianclu (sic). Rumí conoció personalmente al Dr. Tadini, piamontés; a Maenza Stortti, abogado

78 AHN, Consejos, leg. 3855-4. También Vicente Bertrán de Lis era agente, según informa Regato, M., 16 agosto 1830 (AHN, Estado, leg. 3060).

79 Papeles Lafayette, BN, ms. 14613-26.

80 AHN, Estado, leg. 5284-164. Acaso se trate de Morgan O'Connell, el de la expedición a la América del Sur. 
napolitano, a Boarino Tedeschi, hacendado milanés, y a otros dos cuyo nombre no indica ${ }^{81}$.

Incluso Marruecos aparece en estas tramas. Entre los emigrados españoles cundió la noticia de que Juan Rumí había ido a Marruecos en 1828, para negociar en nombre de la Junta de Londres la enajenación de los presidios menores. Los rumores se debieron a una carta de Fernández Golfín, escrita desde Tánger, en la que decía que el Bajá Ominta estaba dispuesto a hacer la propuesta al Emperador (se entiende, a cambio de apoyar las acciones de los liberales). Ominta murió a primeros de octubre de 1829 , y no hubo más. La carta había sido presentada y promovida por el ex Cónsul Zenón de Orive ${ }^{82}$.

\section{Los conspiradores: división socio-profesional}

A estas alturas de la conspiración, conviene detenerse un momento para averiguar quiénes eran los conspiradores, con qué fuerza contaban y cuáles eran sus ideologías y sus propósitos. Por una parte - ya lo sabemos- los conspiradores eran los emigrados, pero en el interior de España encontramos una categoría muy definida: los oficiales del Ejército impurificados, indefinidos e ilimitados, como es el caso del propio Marco-Artu o de Bernardo Márquez en Sevilla y muchos otros. Unos pertenecieron al Ejército liberal en el Trienio, como casi todos los que se entendían con Márquez en Andalucía ${ }^{83}$; otros han estado en América, aunque esa circunstancia tiene carácter doble, reveladora de la guerra civil que fue la Independencia. En el momento de la insurrección de Cádiz alguien escribe desde Málaga, 6 marzo 1831, describiendo los acontecimientos y la marcha probable de la revolución. Por excepción tenemos una descripción del comunicante anónimo:

El que lo escribe es un militar, sentenciado por cuatro años, que fue comprendido en la causa de Porlier o Laci, que estuvo en América y la revolucionó, que tiene un hermano marino, y él lo es, o es artillero, hombre según dicen muy arrojado o temerario ${ }^{84}$.

Cuando la insurrección proyectada puede confiar en antiguos militares realistas, como D. Cristóbal Domingo y el Jefe Santa Cruz en Cuenca,

Causas, t. V, p. 357.

Declaraciones del propio Rumí, Causas, t. V, p. 360.

Causas, t. V, p. 329.

Id., p. 221. 
se da la explicación de que fueron iniciados en América - lo cual probablemente tendrá un sentido masónico ${ }^{85}$ - . En cambio, una información confidencial avisa de que, con excepción de los artilleros, no se puede confiar en Valladolid en ningún oficial, pues todos ellos son malos, «como facciosos y procedentes de América» ${ }^{86}$. Los que en América se han dedicado a la represión, mal pueden dedicarse en España a la revolución. Para todos los demás la ideología ayuda, o sea el liberalismo, pero lo fundamental, me parece a mí, es su condición de impurificados, indefinidos e ilimitados, situación cuyos efectos venían a equivaler a los de la demi-solde francesa, y no necesitan más aclaración (aunque sí acaso los términos en que se expresa). A raíz de descubrirse la conjuración de Marco-Artu el Gobierno lo comprendió perfectamente, e hizo salir de Madrid a unos cuantos militares, sobre los que no recaía más sospecha que su condición de tal: entre ellos encontramos algún nombre conocido, como el de Fernando Alcocer ${ }^{87}$. Los militares son el alma de la revolución, pero también sus mujeres y allegados. Conviene no olvidarlo.

Sorprende un poco ver la alta proporción de curas y frailes comprometidos, señal de que la Iglesia unánime inquisitorial y absolutista que se nos ha querido presentar, no responde del todo a la realidad, y que la tradición del Cura Posse y otros semejantes continúa vigente. Señal también del fracaso, incluso católico, de la década ominosa. Pero para determinar los motivos de cada uno harían falta detallados estudios biográficos, de los que hoy carecemos. De momento tendremos que conformarnos con las Defensas de D. Rafael de Lara, de Fray Juan Bautista Noanaillac, agustino, etc. ${ }^{88}$.

Entre los civiles, llaman la atención los contrabandistas: los de Sevilla y Triana se dice que son preparados por D. Salvador Pérez y un curita joven para la insurrección. Más adelante, en mayo de 1832, veremos a los contrabandistas de Almagro dispuestos a formar guerrillas liberales ${ }^{89}$.

85 Arch. Justicia, Marco-Artu, carpeta 5.

86 Id., carpeta 3.

87 El 19 de marzo 1831. Causas, t. V, p. 373. Sobre Alcocer, cf. mi Rafael del Riego, Madrid, 1976, Tecnos, passim.

88 Cf. Joaquín Pérez Seoane: «Defensa de D. Rafael de Lara y Cárdenas, Pbro.»; el mismo: «Defensa del P. Lector Fr. Juan Bautisma Noanaillac, religioso agustino", ambas en Causas, t. IV, pp. 205-247 y 248-256.

89 Causas, t. V, p. 330, y Arch. Justicia, Marco-Artu, nota del agente llamado el de las 10 y media, M., 11 mayo 1832. 
La infeliz clase de los jornaleros, se nos dice en la región de La Mancha y Sierra Morena, está presta a actuar, pero hay que darle medios y hacerle ver las mejoras que va a ganar ${ }^{90}$. En la zona Guadalajara-Soria-Toledo (sin Madrid) se nos han conservado las profesiones de los comisionados: diez militares, diez propietarios, dos artesanos, un maestro de escuela, un médico ${ }^{91}$. El de Salamanca, Félix Fernández Avilés, es el Alcalde Mayor de la ciudad ${ }^{92}$. Los propietarios o hacendados constituyen una clase relativamente abundante, y muy abundante, pues siempre hace falta dinero, y ellos, como los comerciantes y los banqueros, lo dan o hacen de intermediarios. Por ejemplo, Francisco Javier Albert, comerciante de Madrid, calle del Carmen, recibe el dinero, por el que entregará unos recibos endosados a D. Martín Bahamonde, y pagaderos en la casa de D. Tomás Emperador, todos de Madrid. D. Juan Muguiro Iribarren, comerciante de Madrid, calle de Postas, en noviembre de 1830 recibe 2.000 duros, para hacerlos llegar a Cádiz ${ }^{93}$. El Gobierno sospecha de los Arratías, comerciantes de Madrid, y de Balmaseda, banquero de Madrid, lo mismo que más tarde se sospechará de Vélez y Goycoechea Galarza, también banqueros mảdrileños, que viven en la propia casa del Capitán General ${ }^{94}$. En Granada, junto a 3.000 ciudadanos, se citan 1.500 empleados en las minas, muchos alpujarreños, e incluso personajes de la alta nobleza, entre los que se incluye al Marqués de Campoverde ${ }^{95}$, cosa por lo menos inquietante. Otros obreros mencionados son los trabajadores de la fábrica de tabacos de Sevilla ${ }^{96}$.

A las necesidades de la sociedad española de aquel momento obedece también, según creo, el hecho de que muchos de los dirigentes sean técnicos, como el propio Marco-Artu, ingeniero de categoría, o Valentín Falcato, el jefe de la conspiración en la zona de Badajoz, ingeniero de caminos, que típicamente se valía del P. Guardián de San

90 Arch. Justicia, Marco-Artu, carpeta 6.

91 Id., carpeta 2.

92 Causas, t. V, p. 247.

93 Arch. Justicia, Marco-Artu, carpeta 4.

94 Arch. Justicia, Marco-Artu, carpeta 1; Causas, t. V, p. 364. Sobre Albert y Balmaseda, cf. mi William Maclure, B. 1979, pp. 80-86.

95 Según Santiago Vicente García, Causas, t. V, p. 327. El delator Pacheco dice que supo que Campoverde era el presidente de la Junta de Granada, pero él personalmente no se lo cree (Causas, t. V, p. 288; cit. también en íd. 255).

96 Causas, t. V, p. 329. Cf. con el interesante artículo de Claude Morange: «De la manola à l'ouvrière: La révolte des cigarreras de Madrid en 1830 (notes sur un conflit de travail)", Cahiers de l'UER d'études ibériques, 1, 1977, pp. 108-137. 
Francisco y de D. Manuel Silvestre Cubero, cura de Zafra. Falcato fue también detenido por orden de Calomarde ${ }^{97}$.

Un grupo muy especial de colaboradores lo constituyen los realistas, que sin dejar de serlo, entran en las filas de la conjuración. Como veremos, Espoz y Mina se dirige también a ellos en sus proclamas, y entre los papeles que le fueron cogidos a Marco-Artu figura una proclama realista contra la alteración en el orden de sucesión a la Corona, lo cual indica una voluntad puramente táctica de poner dificultades al Gobierno ${ }^{98}$, no dándose cuenta acaso de lo que va a ser el carlismo. Ya hemos citado algunos realistas, en Cuenca, dentro de la conspiración. Pero hay una categoría que indica probablemente una crisis profunda: me refiero a los voluntarios realistas. Algunos simplemente no quieren luchar contra la revolución, o por lo menos eso se piensa de ellos, por ejemplo en Valencia, enero $1831^{99}$. El Gobierno, por desconfianza o por necesidad, se ve obligado a incautarse de los fondos que obraban en la Inspección General de Voluntarios Realistas ${ }^{100}$. Pero lo más extraordinario es la militancia de F. Herrera, secretario de Subinspector de Voluntarios Realistas, que está de acuerdo'en Sevilla cọn el Coronel Márquez, al que ofrece comunicar los secretos de Grimarest, librar fondos y movilizar realistas, pues de acuerdo con algunos de ellos «tenían concertado el modo de facilitar la empresa y ocupación de las armas, municiones y fuerza que hubiese en el cuartel» ${ }^{101}$. Pudiera tratarse de una celada, pero no necesariamente. El Cuerpo de Voluntarios Realistas, cuya historia está por hacer, había llegado a un grado total de disolución. El Inspector General, D. José María Carvajal y Urrutia, era demasiado viejo, pues había ascendido a Capitán General en 1814 y fallece en $1832^{102}$. Pero esto no lo explica todo. La realidad es que el régimen absolutista tampoco da satisfacción a los voluntarios. Se ha llega-

97 Tadeo Calomarde: Cinco comunicaciones sobre la sorpresa de los corresponsales del rebelde Mina y sus papeles, y causa de D. Valentin Falcato, BN, ms. 12970-14. No he podido encontrar la Historia de Badajoz, que publicó Falcato en Badajoz, 1844. Significativamente, la visita de Miyar a Marco-Artu obedecía a su propósito de traducir el Diccionario tecnológico de artes y oficios y de la economía industrial y comercial, que se publicaba en París. (Causas, t. V, p. 186). Creo que se trata del n. ${ }^{\circ} 73025$ de Palau, del que salieron 8 vols. en Barcelona entre 1833 y 1835 .

Causas, t. V, pp. 322-3.

Arch. Justicia, Marco-Artu, carpeta 5.

Causas, t. V, p. 266.

102

Declaración de Santiago Vicente García, 20 de abril 1831, Causas, t. V, p. 329.

Guía de Forasteros, M., 1831, y Victoriano Encima y Piedra: De los sucesos del real sitio de San Ildefonso, o la Granja, a fines del año de 1832, París, Librería Rosa, 1837, p. 183 . 
do a un límite, por lo que unos se inhiben, otros ingresan lealmente en el liberalismo, y finalmente otros ingresan para reforzar con su presencia la política moderada, y probablemente estamos ya ante los comienzos del fenómeno descrito por Baralt y Fernández Cuesta: a raíz de 1843 los antiguos' Voluntarios Realistas ingresan en la policía secreta del moderantismo ${ }^{103}$. Esto merecería mayor averiguación, pero se sale de mi tema de hoy.

Esta era la gente de la conspiración. Negativamente les unía la incapacidad de evolución del régimen, y positivamente su inmenso deseo de que las cosas cambien. Desde el punto de vista militar, cada Junta, o las más importantes, comunica la fuerza del enemigo, y su buena o mala disposición. Existe un cómputo muy estricto de las unidades adictas y de los movimientos y posibilidades de sus jefes también adictos. Sobre el papel, el panorama es impresionante: 600 caballos en La Mancha, más el Regimiento de Caballería del Príncipe que está en Almagro, el Brigadier Rafael Hoore en Cuenca y provincia, etc. ${ }^{104}$. Así comarca tras comarca o región tras región, y a veces pueblo por pueblo. Pero con frecuencia también una indicación alarmante: faltan fondos, no hay dinero. Así por ejemplo, en la propia Mancha y Sierra Morena ${ }^{105}$, o en Cartagena ${ }^{106}$. En Valladolid se lamenta la miseria de los pueblos y la existencia de muy pocos capitalistas ${ }^{107}$. Afortunadamente se cuenta con buena gente: «Todo Madrid está de levante», se nos dice en $1831^{108}$; efectivamente «se cuenta con la tropa de Marina, gran parte de la Guardia Real, y muchas centurias organizadas con indefinidos y paisanos bajo buenos Jefes» ${ }^{109}$. Y tampoco se carece totalmente de dinero: en Málaga, se dice, han recibido 2.000 duros para el alzamiento. No es extraño que se disponga a ser la primera en pronunciarse, si Cádiz no se decide $^{110}$. Pero en el pronunciamiento de Cádiz se gastaron $70.000 \mathrm{du}$ ros, que se supone dados por los franceses ${ }^{111}$. Algunas ciudades presentan premisas previas antes de decidirse: Murcia, se nos dice, está corriente, es decir, bien preparada, pero exige: $1 .^{\circ}$, que los trabajos pro-

103 Cf. R. M. a Baralt y N. Fernández Cuesta: Historia de las Cortes de 1843 a 1848 , M., Imp. de la Calle de San Vicente, 1849, p. 8.

104 Causas, t. V, p. 313.

105 Arch. Justicia, Marco-Artu, carpeta 6.

106 Id.

107 Id., carpeta 3.

108 Causas, t. V, p. 274.

109 Según Santiago Vicente Garcia, Causas, t. V, p. 310.

110 Causas, t. V, pp. 271 y 312.

111 Id., p. 262. 
cedan de un centro común; $2 .^{\circ}$, que Cartagena se adelante en el movimiento. En consecuencia, Fernández Vallesa, desde Gibraltar, 30 diciembre 1830, incita a los de Cartagena a la acción, para quitar el prurito de preferencias que destruyó a los de la Frontera ${ }^{112}$, es decir, a los de los Pirineos. Con lo cual siempre nos volvemos a encontrar con el tema de la desunión de los liberales españoles.

\section{Revolución europea}

Sobre esta organización la Revolución europea de 1830 penetra como una tromba. Quizá el ejemplo extranjero logrará el milagro, no tanto de la decisión, cuanto de la unión. Una carta de Marco-Artu del 11 de marzo de 1831 dice:

A Málaga que se pronuncien. Métales V. fuego y entusiásmelos V. con las noticias de los Polacos, Piamonteses, Italianos, venida de los Portugueses, huída del Padre Santo, ejércitos franceses, etc., etc. ${ }^{113}$.

Las proclamas de Espoz y Mina hacen alusión a Europa, y al ejemplo de los tres días de Francia, repetidamente, y de Bélgica, Sajonia, toda Alemania. Una carta clandestina, como todas ellas, afirma haberse impreso

200 ejemplares de cada una de las tres proclamas del General, para darlas nuevamente en los cuarteles y extenderlas en el pueblo, habiendo aumentado en ellas la Polonia a continuación de los hechos de libres Franceses e Italianos etc. que expresa ${ }^{114}$.

Es decir, los textos políticos no eran fijos, sino que se adicionaban según los acontecimientos europeos, en espera de poder hacerlo también con los nacionales. Una carta de Burdeos, 2 marzo 1831, comunica la incursión de los piamonteses en su país. Una semana después precisa que la entrada es en Saboya, y habla de la Sociedad Aide-toi. Habla también de los Polacos, que «se han portado como verdaderos héroes y han hecho retirar a los Rusos. Cuándo haremos nosotros algo que se parezca a esto?». En la misma carta se comunica la detención de Pepe en Marsella, y aunque se dice que el Gobierno francés «hasta ahora nos ha contrariado", la guerra es segura -entre Francia y Austria- y esto nos favorece. El autor de la carta ha escrito poco antes:

\footnotetext{
112 Arch. Justicia, Marco-Artu, carpeta 6.

113 Causas, t. V, p. 221.

114 Id., pp. 224 y 260.

115 Id., pp. 247-8.
} 
$\mathrm{Y}$ diga V. a los que se llaman nuestros que no riñan ahora y que al contrario se unan lo posible ${ }^{115}$.

\section{En otro lugar consta que}

El embajador Francés está amenazado cruelmente por medio de infinidad de anónimos que le han dirigido los realistas; está lleno de temores para entrar en cuestión con nosotros, vamos a ver si le garantizamos las personas para sacarle de todo recelo; pues él no se niega a auxiliarnos pero se conoce que camina no con toda seguridad ${ }^{116}$.

\section{El Embajador era el Conde d'Harcourt.}

La muerte de Salvador Manzanares, cuando desembarcó para sublevar Cádiz, no es obstáculo. Marco-Artu sigue insistiendo en que mete fuego a los andaluces para que no se duerman, y se entusiasmen con el ejemplo de los Polacos, Piamonteses, Italianos (sic) ${ }^{117}$.

Aunque posterior a lo de Marco-Artu, merece citarse una proclama de Torrijos de 20 mayo 1831, que empezaba así:

Españoles: Cuando el Universo entero sacude con energía las pesadas cadenas del despotismo y de la tiranía fanática: cuando Francia ha dado una lección al mundo derrocando al verdugo de sus pueblos, a pesar de sus mercenarias tropas arrolladas sólo con piedras y garrotes, vencidas y derrotadas por el valor denodado de los libres: cuando la Polonia no ha temido elevarse con solo tres millones de habitantes contra todo el poder colosal de la Rusia: cuando Italia renueva sus esfuerzos para arrojar los esclavos de la Alemania: cuando la América y aun los negros salvajes han domado y triunfado de las aguerridas tropas de Europa y han adquirido su libertad e independencia, $y$. en fin, cuando hasta los Turcos se levantan ya para abatir al poder insufrible del Sultán ¿sois vosotros solos los que abatidos, encorvados, y al parecer gustosos arrastráis las cadenas y lleváis el sello de la ignominia y de la cobardía en vuestros rostros y frentes?... ${ }^{118}$.

Cuando D. Antonio Fernández del Castillo hace proselitismo con su futuro delator D. Antonio M. ${ }^{a}$ Pacheco, el argumento supremo es el de las jornadas de julio en Francia, además de leerle proclamas de Mina, etc. ${ }^{119}$. Otro delator, Santiago Vicente García, que tiene proble-

\footnotetext{
116 Id., pp. 266-7.
}

117 Id., p. 275. También Regato es puntualmente informado desde París de los acontecimientos de Polonia, Bélgica, etc. Cf. AHN, Estado, leg. 3060.

118 Causas, t. V, p. 277. Un «Manifiesto a la Nación», impreso, de Flores Calderón y Torrijos, en AHN, Estado, leg. 3060 (independencia nacional, libertad justa, buen gobierno). El ms. se encuentra en la Biblioteca Municipal de Madrid, según Luis Ballesteros Robles: Diccionario biografico matritense, M., Imp. Municipal, 1912 , p. 627.

119 Id., p. 286. 
mas de conciencia por su acción, la justifica «atendiendo a los compromisos en que puede poner al Gobierno de S. M. la situación violenta y convulsiva en que se halla la Francia», escrito del 15 de abril de $1831^{120}$. Otro delator, Juan Rumí, atribuye a los revolucionarios franceses la idea de querer proclamar la República, de la que dependía el cumplimiento de las ofertas hechas a los españoles; $y$ añade este lúcido pensamiento:

Interin se conserven de cualquier manera las formas monárquicas, no obtendrán los anarquistas españoles la protección que se les ofreció ${ }^{121}$.

La Revolución europea de 1830 deslumbra a los españoles. Pero hacia dentro siempre el mismo problema. Espoz y Mina se defiende en una carta a Vicente Sancho -el futuro esclavista y denunciador de Romero Alpuente- de las calumnias, según él, que le acusan de ser obstáculo a la formación de una Junta de españoles como la que tienen en París los italianos, los belgas y los polacos ${ }^{122}$.

$\mathrm{Y}$ en un momento de pesimismo, pero también de autenticidad, un artículo titulado De la situation de l'Espagne llega a la conclusión de que en la Francia del siglo XVIII las ideas llevaron al pueblo a la Revolución: en España las teorías no alcanzan al pueblo ${ }^{123}$. Esta es la cuestión. ¿Con qué ideología se intenta, pues, en España la Revolución?

\section{Espoz y Mina}

Acaso la respuesta nos la da Marco-Artu cuando criticando el carácter independiente que se quiere dar la nueva Junta, la de Bringas y demás, que rehúye el depender de los emigrados, se pregunta: «Querré yo Cámaras?», para pasar a decir que no tiene ambición, y que lo suyo es la pura acción, sin pretensiones, pero naturalmente se ve obligado a atacar a los que no marchan o no proceden bien ${ }^{124}$. El plan de Cámaras era el que enarbolaban todos los reaccionarios en el Trienio liberal -se entiende, los que no querían lisa y llanamente el restablecimiento del absolutismo- - . Convertirlo ahora en bandera revolucionaria resultaría bastante contradictorio. Ahora bien, diversos contemporáneos atribu-

120 Id., p. 314.

121 Declaración del 5 de abril 1831, Causas, t. V, pp. 350-1.

La carta está traducida al francés en los papeles Lafayette de la BN de Madrid.

BN, papeles Lafayete. Dice $1^{\text {er }}$ Article. Cf. ahora Clive H. Church: «Succes and failure in 1830», Trienio, $\mathrm{n} .^{\circ} 2$, noviembre 1983, p. 64. 
yen a Espoz y Mina un pensamiento semejante, o incluso peor. Para Puigblanch la Junta de Mina se compone de «la misma laya de jente ambiciosa i pastelera de antaño». En 1830 Mina invita a los españoles a que adopten la forma de gobierno de los ingleses, «es decir, un rei bajo la curatela de los nobles, i un comun pueblo chupado hasta los tuétanos por los nobles i por el rei»» ${ }^{125}$.

Juan Romero Alpuente, en octubre de 1830 - la época de la expedición de Vera- publicó su folleto Observaciones sobre el prestigio errado y funesto del general Espoz y Mina, en el que basándose en Sainz Castellanos y en Puigblanch acusa a Mina de querer introducir las dos Cámaras, grandes y clero, dominando a los del común, aparte de los tremendos cargos de ignorancia, codicia, crueldad, ambición y traición, que se refieren a la época anterior ${ }^{126}$.

Pedro Méndez Vigo le acusa en 1834 de ser «nuevo instrumento para cortar los progresos de la revolución social» ${ }^{127}$. Romero Alpuente, en otro folleto titulado Los tres días grandes de Francia, que fue prohibido en España el 22 de octubre de 1830, se muestra partidario de la jefatura militar de Torrijos, y aunque no menciona expresamente a Mina, él es el excluído ${ }^{128}$. A su vez Pedro Martínez López acusó a Romero Alpuente en 1831 de buscar la desunión de los españoles y de querer mantener a España en perpetua guerra civil y miseria ${ }^{129}$. Conviene, pues, que analicemos el pensamiento de unos y otros.

El mote que usaba el centro madrileño de los partidarios de Mina era Constitución con Fernando o sin él, lo cual desde el punto de vista

Antonio Puigblanch: Opúsculos gramático-satíricos, Londres, s. a., Imp. de Guillermo Guthrie, 2 vols., I, p. XXXIV.

126 En los Pirineos, octubre 1830. Ya el 12 de octubre de 1826 Flórez Estrada, Romero Alpuente, Bertrán de Lis, Rotalde y Vicenta Oliete habían firmado un Manifiesto contra Mina. Cf. Simancas, Estado, leg. 8189. El hecho de que Vicenta Oliete fuese confidente de la policía, hace pensar en la posterior recomendación de Regato sobre «acalórar la animosidad en los partidos de Mina y Torrijos» (1 octubre 1830, AHIN, Estado, 3060).

127 Las Horcas caudinas o la vuelta a España de los patriotas emigrados, París, Imp. de Boudon, 1834, pp. 36-39.

128 Los tres días grandes de Francia y los medios de llegar a ver otros iguales en la infeliz España, fechado en Pirineos, septiembre 1830. La prohibición en AHN, Consejos, leg. 3853-2.

129 Appel aux Espagnols. Par un refugié de la même nation, Bergerac, Faisandier, juin 1831 (atribución de José M. a Azcona: Zúmalacárregui, M., Instituto de Estudios Políticos, 1946, p. 269). También Martínez López era agente de policía. 
revolucionario no parece excesivo ${ }^{130}$. Las proclamas lanzadas por Espoz y Mina expresan bastante bien su programa. Según él mismo dice en sus Memorias en Vera repartió cinco proclamas, que inserta numeradas: La 1. a predica la unión, lejos del despotismo de la autoridad y del desorden de los que quieren ensanchar las franquezas y libertades públicas. Ejemplos de Francia e Inglaterra, que hay que imitar:

Imitémoslas también en las instituciones que las rigen, según las cuales poniéndonos en armonía con ellas y con los otros países constitucionales de Europa, echaremos las dos grandes bases de la prosperidad de los Estados, la libertad y el orden. La nación española reunida por medio de sus representantes y amaestrada con las lecciones de la experiencia, adoptará sin duda un gobierno libre, en que no menos se hallen asegurados los derechos de todos los españoles, que las prerrogativas de la corona.

Habla después de promover la riqueza pública, de terminar las desavenencias de América, de cumplir religiosamente los contratos, etc.

La número 2, dirigida a los militares españoles, predica de nuevo la unión, y un «entero olvido de lo pasado»:

Militares del ejército, Milicianos provinciales, Voluntarios realistas: allá vamos con los brazos abiertos y con los pechos desnudos. Venid a reuniros con nosotros: allá vamos a abrazaros a todos como hermanos.

La 3, dirigida a los milicianos provinciales, les recuerda las doctrinas de paz del Evangelio y les invita a no disparar. Añade:

Milicianos: De un momento a otro nos veréis en el territorio español llevando a nuestra cabeza al general Mina, cuyo nombre os es bien conocido. Al instante se instalará el Gobierno para que haya orden y tranquilidad desde el primer día, y vosotros tendréis al momento el permiso para volveros a cuidar de vuestras familias y de vuestras labores.

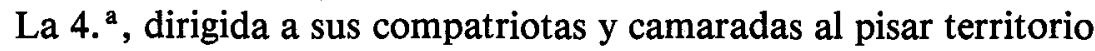
español, predica orden y unión, libertad, gloria y prosperidad nacional:

Para mejor conseguirla, para evitar toda divergencia y todo abuso, es indispensable establecer lo más pronto posible una autoridad provisional conservadora de las leyes, a la cual obedezcamos todos desde luego, hasta que libre la nación, o alguna parte considerable de ella, determine otra cosa que más conveniente sea. En el primer pueblo español, cuando las circunstancias lo permitan procederemos a elegir esa autoridad provisional, tan necesaria.

La $5 .^{\text {a }}$, más que una proclama, es un bando, en el que Mina ordena el más riguroso respeto por todos y por todo, y determina cómo

130 Según noticia enviada el 8 enero 1831 por el embajador español en Londres (Causas, t. V, p. 369). 
debe ser avituallado el Ejército ${ }^{131}$. Además de estas proclamas, en los papeles de Marco-Artu se encontró otra, sin fecha, pero que confirma los extremos de conciliación de los anteriores. Dice que los que «han sufrido todo género de desgracias, persecuciones y hasta la proscripción», vuelven a la patria,

no con los sentimientos que les suponen sus mortales enemigos de robar, de asesinar, de destruir, de vengarse en fin de los males y ultrajes que han sufrido, sino con la idea bien contraria de abrazar a sus hermanos, de mezclar lágrimas de ternura con éstos al renovar la memoria de aquellos días de tranquilidad que gozaron en otro tiempo, y en suma, vuelven a sus hogares para hallar en ellos la paz, para establecerla si no existe, y para consolidar la unión, la concordia entre todos los españoles, y contribuir a que la nación entera se fije un modo estable de gobierno, que concilie todos los intereses, y que la haga feliz en todo sentido...

Unión, paz, tranquilidad, orden y seguridad. «Estos son sus intentos, y los resultados no pueden fallar cuando es obra de valientes que dirige el General Mina ${ }^{132}$.

Otra proclama anónima, dirigida a los realistas -a la que ya he aludido antes - les invitaba a rechazar la modificación introducida en el orden de sucesión a la Corona. Pero en fin, aunque se encontró entre los papeles de Marco-Artu, no es seguro que se deba a la mano de Espoz. Sí lo es otra proclama, fechada en Bayona el 3 de enero de 1831, posterior por tanto a los sucesos de Vera de Bidasoa, en la que Mina insiste en la buena ocasión que la situación de Europa ofrece a España, y en que ésta no debe desaprovecharla:

La dificultad está en si lo hará por medio de una convulsión espantosa o de un plan ordenado en cuanto cabe. Todos mis conatos se dirigen a evitar que llegue el primer caso, porque entonces se daría lugar a un trastorno general de todas las fortunas, que yo quiero evitar a toda costa como lo he sentado en los papeles que he hecho circular con mi nombre.

Es decir, ha procurado siempre evitar una revolución. Consecuentemente el resto de la proclama lo dedica a pedir al comercio de Madrid que le adelante dinero en «calidad de préstamo con interés o sin él»" ${ }^{133}$.

Estas ideas se explayan en la Instrucción del Comisionado principal de Madrid a los comisionados de provincia, fechado el 11 de octu-

131 Cf. Espoz y Mina: Memorias, M., B. A. E., 1962, t. II, pp. 164-167, y Causas, t. V, pp. 222 y 229-31. Resúmenes de Arch. Justicia, Marco-Artu, carpetas 8 y 9. Hay algunas variantes, no muy importantes, entre los textos de las Memorias y los de Causas.

Causas, t.V, p. 230.

133

Id., pp. 227-8. 
bre de 1830, y que es un documento interesantísimo. Consta de 22 artículos: el $1 .^{\circ}$ deja en manos del General Mina anunciar la época del rompimiento. Los otros artículos señalan el grito de guerra de Viva la libertad, el motivo de la insurrección —restablecer a la nación en sus derechos-, actuando contra la «imbécil facción» que se apoderó del mando en 1823 . El artículo $4 .^{\circ}$ reproduce ideas ya conocidas:

Deben evitarse a toda costa las venganzas particulares, proclamando un absoluto olvido de lo pasado, el cual se observará religiosamente con todos los que contribuyen o no se opongan al restablecimiento de la libertad.

$\mathrm{El}$ artículo siguiente, el $5 .^{\circ}$, nos sorprende por su barbarie:

El Clero secular y regular no queda comprendido en lo dispuesto en el artículo anterior, pues siendo en esta clase en donde se halla el mayor y casi exclusivo número de nuestros enemigos, debe procurarse el exterminio de los malos por todo los medios posibles, desde el momento en que los patriotas se crean bastante fuertes para considerar asegurado el triunfo.

Los artículos 6 al 9 disponen la incorporación a las filas nacionales de las tropas enemigas, Milicias y Guardia Real, conservando los oficiales sus grados. Los prisioneros cogidos en acción de guerra serán enviados a casa si se trata de soldados, cabos y sargentos, que no quieran sumarse al ejército patriota; los oficiales serán fusilados en el acto, aunque el vencedor podrá conceder gracia. Importancia extraordinaria tiene lo relativo a los voluntarios realistas, que merece ser citado in extenso:

10. Como el mayor número de Voluntarios-realistas se ha alistado por efecto de la seducción y del engaño de nuestros comunes enemigos, se les hará entender por todos medios, que los patriotas lejos de aspirar a ningún género de venganza, desean y les invitan a tomar parte en la grande obra de nuestra regeneración política, dispuestos a proteger como a compañeros y hermanos a todos los que se decidan. 11. En garantía de lo dispuesto en el artículo anterior, se establece que todos los Voluntarios realistas que se presenten con las armas en las manos para ayudar a los patriotas no sólo serán protegidos contra todo insulto y vejación en su persona y propiedades, sino que se les conservará armados, y serán admitidos en las filas nacionales en la misma forma que los demás patriotas, quedando además prohibida respecto de ellos toda pesquisa sobre hechos anteriores a la fecha en que verifiquen su presentación. 12. Los Voluntarios realistas que no se presenten en las filas nacionales, pero que permanezcan tranquilos en sus hogares y entreguen a los patriotas su armamento, municiones y demás, serán protegidos en sus personas y propiedades del mismo modo que se dispone en el artículo anterior. 13. Los Voluntarios realistas que olvidados de lo que deben a su patria, continúen sosteniendo la causa injusta de nuestros opresores, y sean aprendidos [sic] con las armas en la mano, quedarán a discreción del vencedor, que los fusilará en el acto, o castigará a su arbitrio, según le pareciere. 14. Lo dispuesto en los artículos anteriores con respecto a los Voluntarios realistas se entiende igualmente para con cualquiera gente que se haya armado de orden del gobierno, o de las autoridades respectivas de las provincias. [...]. 
19. Con los Voluntarios realistas y demás patriotas que se presenten con las armas en la mano para sostener la causa de la libertad se formarán batallones con el título de Voluntarios de ... [el nombre de la Provincia; distinguiéndose por los números $1 .^{\circ}, 2 .^{\circ}$, etc.]. Estos voluntarios podrán dejar las armas y retirarse a sus casas, luego que esté asegurado el triunfo de la libertad.

El resto de los artículos dispone el nombramiento en todas las provincias de un jefe militar «que se encargue del gobierno superior de la provincia en todos los ramos con poder ilimitado y discrecional para ejecutar cuantas órdenes se le comuniquen por el Gl. M. o el Gobierno que éste organice, y dictar las demás que crea conducentes para consolidar la libertad»; y del nombramiento también de Juntas provinciales, con las que consulte el Gobernador, aun no estando obligado a seguir sus determinaciones; y de los ayuntamientos de los pueblos, con personas nombradas por el Gobernador. Estas instrucciones podrán variarse si llegan otras del General Mina ${ }^{134}$.

Aparte de que con el espíritu de estas instrucciones queda ya predeterminado el Convenio de Vergara, lo que se ocurre pensar es que Espoz y Mina, con palabras de libertad, estaba organizando su propia dictadura con los mínimos cambios sociales y políticos. Su revolución, todo lo más, consistía en un cambio de personas en la cima y en cierta dosis de anticlericalismo. No es extraño que los sinceros revolucionarios liberales le atacasen, y por otra parte no es extraño que la conspiración fracasase. Y esto aun teniendo en cuenta el carácter equívoco de la militancia en el interior, ya que muchos no conocían ni siquiera al lejano Principal, y creían luchar por un recuerdo de la Constitución, como la habían vivido en 1820; y otros que conocían a Mina y deseaban ser independientes, no rechazaban sin embargo el valor de una organización militar. La difícil clandestinidad y las actitudes equívocas de muchos contribuían a oscurecer las finalidades últimas de la acción.

Si de Espoz y Mina y sus inmediatos seguidores pasamos a una Junta como la de Sevilla, que desconfía de él y no está de acuerdo con Torrijos, nos encontramos con que su pensamiento político deriva sobre todo del miedo a la plebe, a la que supone partidaria del robo y del pillaje, y en consecuencia la Junta y Bernardo Márquez a su cabeza se

134 Id., pp. 233-5. Según Arch. Justicia, Marco-Artu, carpeta 10, esta instrucción emana de la Conjuración de liberales españoles para el establecimiento de un gobierno nacional, cuyo reglamente a base de comisionados y Juntas provinciales consta en Causas, t. V, pp. 238-43. En ella los juramentos se hacen por los manes del Empecinado y de Chapalangarra. 
dedican a comprimir la revolución cuando ésta amenaza, en marzo de 1831 , y a pensar que

el único recurso que podía salvar a la Nación, [era] el pedir a S. M. por una aclamación general que se dignase llevar a efecto las promesas que hizo por su real decreto dado en Valencia a 4 de mayo de $1814^{135}$.

Causa pena pensar la sangre que corrió para tan poca cosa.

Tampoco la Junta de Londres, si hemos de creer a Juan Rumí, tenía en la época anterior a la expedición de Vera excesiva confianza en la revolución. Invitado por Torrijos a exponer ante la Junta los principios políticos que, en su opinión, serían del agrado de los españoles, confeccionó una Memoria, que leyó ante la Junta:

[...] Probé en ella entre otras cosas que la nación española en manera alguna se hallaba dispuesta a una revolución, pero que en el caso de que contra toda probabilidad se consiguiese emprenderla, todo lo que fuera excederse de los principios de una Monarquía moderada hereditaria, o atacar la dinastía legítima sería enajenarse seguramente al pueblo que hubiera tomado parte en ella. Mi escrito fue aplaudido, aunque en la discusión no fueron aprobadas sus máximas...

La Junta nombró una comisión, llamada de política, para discutir la Memoria de Rumí y emitir un informe. Compuesta la comisión por Flores Calderón, Flórez Estrada, Evaristo San Miguel y Calatrava, más Rumí que hacía de secretario, volvió éste a escribir otra Memoria en defensa de la primera y de los principios moderados que había sostenido, «la que convenció y según he sabido después se arregló sobre ella el informe», según dice ufano de su triunfo y en desprecio de aquellos revolucionarios ${ }^{136}$.

\section{Romero Alpuente}

No todos los revolucionarios tenían tan poca entidad, ni hay que aceptar el juicio de Rumí, al fin y al cabo un traidor, como si fuese el Evangelio. Juan Romero Alpuente, en el folleto ya citado Los tres días grandes de Francia, expone un programa bastante coherente: Francia, ahora liberal, está obligada a ayudar a la libertad española, porque fue autora de la tiranía. Reproduzcamos las palabras del viejo jurista, acostumbrado a leer las Partidas:

Declaración de Santiago Vicente García, Causas, t. V, pp. 308-9.

Causas, t. V, p. 355. 
El rey Fernando por su conducta opresora y sin sujeción alguna a ninguna ley de las que tantas veces ha jurado guardar, es un rey torticero contra quien hasta los viejos y las mujeres tienen derecho para alzarse con arreglo a las leyes fundamentales de la monarquía.

Nada de introducir en España una Regencia o Junta hecha en París o en Londres. Nada de ministros y diputados, que perdieron la libertad en 1823: ni siquiera el haber votado la incapacidad del Rey es un mérito, pues debieron haber votado incapacidad ilimitada y no temporal. El único militar decente es Torrijos, y él debe dirigir la campaña. Los militares deben alegar su valor actual, y no méritos antiguos. Los militares deben guardar la disciplina, y no dedicarse al robo ni al asesinato. En cuanto a las medidas políticas, habrá que restituir los ayuntamientos y las diputaciones provinciales que había en 1823, con carácter provisional, pero no se debe incurrir en irreligiosidad ni en asesinatos, ni se puede dejar a nadie, aunque sea el más fanático, sin posibilidad de comer $^{137}$.

\section{La insurrección de Cádiz}

Fracasada la expedición de Vera, y fracasados también Manzanares y Torrijos en su primer desembarco en Algeciras (febrero de 1831), la gran conspiración urdida bajo su nombre y los de Mina y MarcoArtu fracasa también, apenas iniciada en Cádiz. En este punto el alzamiento estaba previsto para el día 2 de marzo de 1831, pero no se hizo hasta el siguiente. El día 2 se recibió una carta de Torrijos pidiendo la colaboración de los gaditanos, y todo parecía que iba a ser un éxito. El plan acordado era el arresto del Gobernador - Antonio del Hierro y Oliver, que será muerto el día del levantamiento- y a continuación el Teniente Coronel Mayor del Regimiento del Rey, D. Felipe Ribero, debía pronunciarse a la cabeza de su Regimiento, y lo mismo harían las demás unidades, arrestando a quien no fuese adicto. Aunque los $p a$ triotas estaban mal armados, se les organizó en pelotones para acudir a los puntos más importantes: a su cargo estaba arrestar al Gobernador, liberar a los presos de la cárcel y apoderarse de la Tesorería de la Junta de Comercio. A continuación se proclamaría un Gobierno provisional, con Presidente Nato (ignoro a quién se refiere). Vicepresidente Torri-

137 Cf. n. 119. Dirigiéndose al mismo tiempo a los aragoneses, Romero Alpuente les recordaba la deposición de Carlos X, invitándoles a hacer lo mismo con Fernando, y a apoyar por ello a los bravos que iniciaban la invasión. Cf. "Aragonais», traducido en Journal des débats, 25 octubre 1830 (conste aquí mi agradecimiento a J. R. Aymes, que copió este texto para mi). 
jos, y en su ausencia Felipe Ribero, quien quedaba así de presidente de la Junta que se iba a formar. Una señal daría la orden de insurrección también a la Isla. Comenzó efectivamente el asalto a la casa del Gobernador, y por las calles de la Verónica y Ancha, pero cuando parte del pueblo se dirigía hacia los cuarteles,

el infame RIBERO en vez de cumplir su palabra de honor, ordenó hacer fuego a todo el mundo, y puesto a la cabeza de su Regimiento se dirigió hacia la plaza de San Antonio de donde salieron grandes patrullas baleando a cuantos se les antojaban: los patriotas no tuvieron fuerza bastante para acometer y quedamos en Cádiz sujetos a la arbitrariedad más despótica ${ }^{138}$.

A consecuencia de este fracaso no se levantaron, como estaba previsto, Granada, Málaga, Cartagena, Valencia, Murcia, Valladolid, Salamanca y la plaza fundamental, para esta región de España, Ciudad Rodrigo ${ }^{139}$, y el movimiento se deshizo rápidamente.

Marco-Artu, sin embargo, no se consideraba vencido. Las cosas seguían su rumbo. Dirigiéndose a los de Bayona, escribía:

Me predican V.V. para que no sea fogoso, para que no riña, etc., etc., pero quieren V.V. que me sea indiferente ver que los patriotas que vociferan ser liberales y critican las operaciones de los que son más puros, y más decididos que ellos, se meten en un rincón y sólo sirven para dar consejos que tomando por alcahueta la prudencia quieren escusarse con ella. Estos días empezaba a picarse el entusiasmo un poco, se presentaban a cooperar a resultas de lo de la $I s l a$, pero al momento que vieron desgraciada la empresa, sale a relucir la prudencia y hasta los anónimos, pues me han dirigido estos días, diciendo que deba salir de Madrid, que me siguen, que me vigilan... ${ }^{140}$.

Salvó la piel, como sabemos, aunque los Diarios de Arias Teijeiro están llenos de entradas, en diversas fechas, sobre la prisión del fugitivo, todas falsas: indicio claro de las ganas que le tenían los absolutistas $^{141}$.

\section{Comité Director de la Emigración}

Los sucesos de Vera y de Cádiz y toda la experiencia acumulada hi-

Causas, t. V, pp. 256-8.

139 La importancia de Ciudad Rodrigo es atestiguada en Arch. Justicia, Marco-Artu, carpeta 3.

140 Causas, t. V, pp. 275-6. Para otras insurrecciones en la «década ominosa», cf. mi art. «La contrarrevolución fernandina», Historia 16, extra III, junio 1977 , pp. 7-26.

141 Arias Teijeiro: Diarios. Introducción y notas de Ana M. ${ }^{\text {a }}$ Berazaluce, Pamplona, Universidad de Navarra, 1966-7, tomo III, pássim. 
cieron pensar a los emigrados en la necesidad de proceder a una reestructuración política. El 30 de mayo de 1831 dos tercios de los españoles presentes en París nombraron una comisión, que se encargaría de convocar elecciones para nombrar un Comité Director de la Emigración. Las elecciones tuvieron lugar el 31 de julio. Votaron 970 españoles, residentes en Francia y en otros sitios, y los resultados fueron los siguientes:

VOTOS

D. Alvaro Flórez Estrada, Intendente Militar ......... 868

D. José María Torrijos, Mariscal de Campo.......... 823

D. Manuel Flores Calderón, Diputado a Cortes ....... 772

D. Vicente Cabanilles, primer Alcalde constitucional de Barcelona .......................................... 447

D. Ramón Villalba, Teniente General................ 344

D. Juan López Pinto, Jefe Político de Calatayud ..... 332

D. José María Peón y Mier, primer Adjunto General de Estado Mayor.................................. $\quad 312$

Estos siete, pues, fueron nombrados para el Comité Director. Obtuvieron también votos los siguientes:

D. Francisco Javier Istúriz, Diputado a Cortes ....... 294

D. Juan Romero Alpuente, Magistrado .............. 279

D. Manuel Gurrea, Coronel........................... 249

D. José María Calatrava, Ministro de Gracia y Justicia ................................................. $\quad 213$

D. Francisco Espoz y Mina, Teniente General ........ 176

D. Antonio Vidal, negociante........................ 147

D. Francisco Valdés, Coronel......................... 136

Firman el Acta, París 1 agosto 1831, Alvaro Flórez Estrada, Presidente de la Comisión, José de Castellar, J. L. Ochoa, P. Méndez Vigo, Francisco Valdés, J. A. de Llinás, J. M. Peón y Mier, suplente, y los secretarios Ramón Ceruti y M. Paz Gómez ${ }^{142}$.

Pero un grupo de españoles se negó inmediatamente a reconocer estos resultados, enviando para ello un artículo con fecha 9 de agosto de 1831 al Journal du Commerce, de París, en cuyo número del 15 se

142 Archives Nationales, París, $\mathrm{F}^{7} 12.083, \mathrm{n} .^{\circ}$ 35, carpeta titulada Junte provinciale directrice de la Catalogne. Nicolás Santiago Rotalde dirigió una Acción de gracias a los Señores de la Comisión convocante para la unión de los emigrados españoles, París, 18 junio 1831 (AHN, Estado, leg. 3060). 
publicó. Los disidentes eran Francisco Espoz y Mina, Teniente General; J. M. Vadillo, antiguo Diputado, ex Ministro; A. Alcalá Galiano, Diputado de 1823; X. Istúriz, íd.; A. de Saavedra, íd.; R. Gil de la Cuadra, íd.; V. Silva, íd.; J. Rico, íd.; J. Gil Orduña, íd.; D. de Torres, Intendente General del Ejército; J. P. de Meca, G. de Aguilera, J. Clemente, J. Aldaz, Manuel de Inglan; siguen las firmas ${ }^{143}$.

A esta época deben de corresponder las quince Bases de una nueva regularización de trabajos Patrióticos, que ordenan circunspección, volver a organizar la correspondencia con el interior, subordinar todas las empresas y el gasto de los fondos a un plan central, que no se empiece ninguna operación militar antes de tener «formados depósitos de armas, vestuarios, municiones, etc.», así como la competencia de las personas - sobre todo que no pequen por omisión-y su decisión política; ocuparse más de los enemigos que de los amigos, y que «a la parte sublime de nuestros trabajos» sólo accedan personas muy probadas. La base $n .^{\circ} 11$ es particularmente importante:

$11 .^{a}$ Que en el caso de unirnos con el partido liberal desidente [sic] y formar con él en el extranjero una junta o comisión que represente todos los emigrados, ésta se forme bajo el principio equitativo de que cada partido nombre tres y el $7 .^{\circ}$ a la suerte, poniendo en una urna siete Individuos de cada partido,

es decir, se insistía en los viejos métodos de los pactos entre masones y comuneros, a pesar del mal resultado que hasta entonces habían dado. Después de indicar que estas bases no se deben comunicar a voleo, y que habrá que saber cumplir las obligaciones contraídas, se declara por ahora incursos en esta nueva regularización a Torrijos, Flores Calderón, Valdés, Gurrea, Pinto (Ign.), Minuissir, Paz Gómez, Hernández y Ruiz. La última base difiere bastante de las posiciones de Espoz y Mina:

15. " La fe política de los individuos que guardarán estas bases es la destrucción de la actual dinastía de España; la reforma rádical de los abusos, el establecimiento de nuevas instituciones que aseguren la libertad civil, religiosa y comercial, y el establecimiento del jurado bajo la forma de Gobierno que la Nación ya libre eligiese ${ }^{144}$.

Y probablemente también corresponde a este momento la Instrucción para pláticas a los soldados, cuyo único dato temporal es que en

143 Cf. Galería militar contemporánea, M., 1846, Hortelano y Cía., I, p. 71. Observemos de paso en qué bando está colocado Istúriz: acaso esto nos ayude a entender su repentina conversión al moderantismo unos años después.

BN, papeles Lafayette, ms. $14613^{26}$. 
ella se habla de la muerte de Chapalangarra. Llama la atención ver a un magistrado dando consejos de milicia elementales, sacados de la Antigüedad clásica, de Federico el Grande, de Turena, etc., pero no hay -y es curioso- ningún ejemplo a base del ejército napoleónico ${ }^{145}$.

\section{Nuevas tramas}

La desarticulación de todas las tramas de Marco-Artu no devolvió la tranquilidad al Gobierno de Madrid. A comienzos de abril de 1831 un anónimo avisó al Superintendente general de Policía de que se cernía sobre Madrid una espantosa revolución. El plan nos parecería quimérico y muy de época si no pensásemos en sucesos posteriores de la propia ciudad de Madrid. Aun así la cosa parece salida de una imaginación absolutista: la revolución estallaría el día en que Sus Majestades y Altezas abandonen Aranjuez para ir a los toros. El 12 de abril se supo que hay 400 hombres confabulados, casi todos milicianos, a quienes se les da 3 reales diarios, que suben a 12 los días de acción, más promesa de colocación posterior. Hay muchos comerciantes que contribuyen económicamente, y en cada barrio hay un capataz que paga los sábados. Todo comenzará en la plaza de toros, matando a los centinelas de los tendidos y disparando dos o tres cohetes; entonces saldrán de las tabernas situadas alrededor de la calle de Alcalá muchos conjurados, quienes sorprenderán el Cuartel de Artillería de los Realistas y el del Pósito. Un boticario y unos droguistas disponen lo necesario para sembrar la alarma general: quemarán probablemente el Gabinete de Historia Natural, la cárcel y Casa de la Villa y el palacio de los Consejos, y ofrecerán mucho dinero al pueblo bajo. Mendizábal anda en esto. Los pelotones serán mandados por Melero o Merello, perfumista; Aspiroz, sombrerero; Alvarez, empleado, y su amigo Rozas, y también por un torero. Los planes parecen haber sido discurridos por un tal Wals y por D. Lorenzo Vellens y Villamar, o por el brigadier Zarco del Valle y el Conde de Veva. Se completan con el reparto de dinero entre los soldados, para que envenenen los ranchos y las tinajas de agua ${ }^{146}$.

145 Id. Se trata de un texto muy diferente del de las Instrucciones político militares para los Generales dignos del nombre Español que traten de restablecer la libertad en su Patria, fechadas a 2 octubre 1826, y firmadas por Brutus, Catón, Samuel (Simancas, Estado, leg. 8189). En la Lista de los Masones hallados que componen varias Logias de Madrid y otros puntos (Archivo General de Palacio, P. R. 67, ff. 158 y ss.) el sobrenombre de Bruto lo llevan Antonio Quiroga, Conde de la Bisbal y Ramón Narváez, y el de Catón, Felipe Navarro, Lorenzo Calvo de Rozas y Ramón Gil de la Cuadra.

146 Causas, t. V, pp. 364-5, aviso de Calomarde del 8 mayo 1831. 
El 5 de mayo de 1831 creía saber Calomarde que se preparaba una «conspiración» (sic, la palabra adquiere el valor de estallido revolucionario) en Madrid para el 15 del mismo mes, acaso por coincidir con la festividad de San Isidro: se reunirían en la Plaza Mayor 5.000 hombres con uniformes de caballería, infantería y realistas, y a continuación soltarían a los presos y proclamarían la libertad ${ }^{147}$. Parece mentira que noticias de esta clase sean objeto de una comunicación oficial, pero es que el Gobierno debía de vivir increíblemente atemorizado.

Veamos ahora las nuevas proposiciones de Conti. El 24 de mayo de 1831 escribe Ofalia que se le ha presentado, y le ha informado de que los revolucionarios de Francia preparan una segunda revolución contra su actual Gobierno y Rey, y para ello intentan hacer el movimiento general, desde Lisboa hasta Petersburgo. Los carbonarios dirigen el movimiento, seguidos de otras sectas. Los franceses quieren amalgamar en un solo partido a los revoltosos españoles, y llevar la revolución a España y Portugal. Conti ofrece introducirse en las filas de esta conjuración universal, pero no limitar su papel al de informador, sino crear un centro de actividad en el sentido del partido más exaltado de Francia y atraer a él a los revolucionarios más decididos. Controlando la dirección del centro, se le puede dar la inclinación que nos convenga. También ofrece publicar un periódico en francés, exaltado y republicano, que ataque al Gobierno actual y al catolicismo, a fin de provocar la movilización antirrevolucionaria del clero. Un periódico así -añadeproyectan en Bayona los comuneros y los masones ${ }^{148}$. Por este servicio Ofalia le asigna 150 francos mensuales. El 27 de febrero de 1832 reconoce Ofalia que las revelaciones de Conti no son muy importantes, pero que por lo menos le mantiene informado de lo que hacen los revolucionarios franceses, polacos y otros ${ }^{149}$.

La situación en España quizá no dio lugar a estas fantasmagorías, pero sí a un renacimiento de la conspiración de Marco-Artu, aunque con la ausencia forzada de su antiguo principal. El agente de Calomarde conocido por el mote de el de las 101/2 de la noche, es decir probable-

147 Id.

148 No he podido ver el Grito de la Península, diario que en 1830 se iba a publicar en Bayona, y que es prohibido en Madrid el 31 agosto 1830 (AHN, Consejos, leg. 3855-3). Tampoco he visto El Filántropo, periódico de París, prohibido en España el 30 julio 1832 (AHN, Consejos, leg. 3910-4), ni el folleto El grito patriótico o canción nacional española, prohibido el 30 septiembre 1832 (AHN, Consejos, leg. 3910-1).

149 AHN, Estado, leg. 5284-164. 
mente el médico Maximiano González, había sido el descubridor de la conspiración, según escribió el 19 de agosto de 1831:

Tuve la dicha de librar a la Patria de la horrorosa y sangrienta revolución preparada en Marzo; esta consideración es lo único que calma la amargura de mi alma al considerar que las víctimas que las leyes tienen necesidad de sacrificar, las he entregado yo ${ }^{150}$.

El mismo se va a encargar de la nueva etapa de la conspiración, cuando en junio de 1831 avisa de que una señora que hizo la revolución en América ha salido hacia Francia, para buscar a Mina y a Malcuarto (sic, por Marco-Artu). Después de visitar Bayona y Burdeos y de hablar con Malcuarto y Arizcun, ha vuelto a los 19 días con cartas pidiendo dinero, con instrucciones de poner de acuerdo a los revolucionarios, y también con las de proceder a la organización de una Junta. Sabemos que el banquero Balmaseda y el negociante Carrasco se negaron a pagar a la señora, a pesar de que Carrasco por lo menos estaba en relación evidente con Mina, pues recibió de él dos libros en cifra (que nadie supo descifrar). La señora llevaba una letra de mil duros, cantidad probablemente demasiado fuerte.

En el terreno estrictamente político, junto a las noticias de la formación de una Junta en París en junio de 1831, de la que formarían parte García, el de la Secretaría de Guerra, y Olózaga, y que estaría en relación con Lafayette, la Junta de Madrid va a llevar una donosa trayectoria ${ }^{151}$. La señora, que tenía que organizarla, cree que el de las $10 y$ media ya la ha formado, aunque guarda el secreto que es de rigor; y éste, no sólo no la saca de su equívoco, sino que sonsaca a los revolucionarios toda clase de documentos en nombre de la Junta, y los pasa a Calomarde: éste los devuelve una vez leídos, y reingresan en la circulación liberal. De esta manera la Junta realmente eran Calomarde y sus íntimos; y de esta manera también los papeles de Nicolás Mellado, que

150 Arch. Justicia, Marco-Artu. Corrijo la ortografía del original. Mientras no se indique otra fuente, lo que sigue procede de aquí.

151 En Londres, sin embargo, Manuel Bertrán de Lis se dice representante de una Junta directiva de Madrid. Pertenecía también a una Junta Patriótica del Principado de Cataluña, en abril de 1831, que buscaba la negociación con la ex América española, la independencia de Cuba y la insurrección liberal en España. Trataron de ganarse para sus fines a Miguel del Riego. Cf. mi trabajo «Una lettera di Mazzini a Miguel del Riego", Rivista Storica Italiana, III, 1976, pp. 543-4. Según el impreso La Junta Provincial Directiva de Cataluña, París, Imp. de Selligue, s. a., (1831), 8 págs., la Junta se componía de Francisco Milảns del Bosch, presidente; Antonio Baiges, Felio Rovira y Galcerán, Thomas Raset, Mariano Goucer (ausente), vocales, y Pablo Janer, vocal secretarib, los cuales el 4 de julio de 1831 nombran comisionados a Baiges, Bertrán de Lis y a D. Andrés Borrego (AHN, Estado, leg. 3060). 
viene a ser el Marco-Artu de la nueva etapa, ingresaron en el Ministerio de Justicia, y llegaron a nuestro conocimiento.

Vuelven los mismos pasos que anteriormente, cálculo de fuerzas, etc., y esperanza mesiánica en D. Pedro del Brasil. Pero, hay que ser objetivos, aparentemente no les falta razón: el 17 de marzo de 1832 èl Gobierno español prohíbe el manifiesto de D. Pedro y la proclama del Almirante inglés Sertorius ${ }^{152}$. Se trata del manifiesto del 2 de febrero de 1832, que traducido al español e impreso con notas se encuentra en los papeles Lafayette de la BN. Efectivamente, otro revolucionario de corazón, el valenciano Mariano Mestre, es partidario del rompimiento en cuanto D. Pedro desemboque en Lisboa: asalto del Palacio, acompañado de pronunciamientos en Cartagena, Valencia, Murviedro y Ciudad Rodrigo, y entrada de Mina aunque sólo sea con cien hombres, según comunica el de las 10 y media el 9 de marzo de 1832.

Mellado parece tener mucho predicamento entre la tropa y paisanos, sobre todo a través de otro llamado Mena. Otro revolucionario, llamado Villalonga, quien proyecta entrevistarle con el ex Emperador, es el Venerable de una Logia llamada al parecer Taller de la Unión: en febrero de 1832 va a buscar al de las 10 y media para formar el Gran Capítulo General, que se compondrá de siete o nueve luces, o sea individuos. Los cinco, Mestre, Mellado, Mena, Villalonga y el de las 101/2 discurren un procedimiento para hacerse con dinero con el cual llevar a efecto la revolución: negociar un préstamo sobre un mayorazgo, o más exactamente, préstamo de 30 a 40.000 rs. negociado entre Mena y Mellado, con garantía de Mestre sobre un dinero en Valencia ganado dos veces en un pleito (sic). Mestre parece haber estado al servicio de Espoz y Mina desde 1819, cosa que el de las 10 y media interpreta en el sentido de que habría sido compañero de Richart (sic, agosto 1832).

Las cosas se complican, ya en febrero de 1832 , por la llegada a Madrid de un nuevo personaje: Antonio Sierra y Mariscal, que viene para activar la revolución, como representante oficioso de D. Pedro, a fin de iniciar los contactos. Se presenta a un antiguo seguidor de Marco-Artu, quien lo presenta a Mellado, y éste a su vez al de las 10 y media: manifiesta no confiar en los emigrados, por sus desavenencias, habla contra los generales constitucionales de la época del Trienio y contra Torrijos, en particular. Lleva mucho dinero (40.000 duros). Es hombre libre, pe-

152 AHN, Consejos, leg. 3910-5. Flórez Estrada no se muestra demasiado entusiasta ante el manifiesto, aunque reconoce que no es malo y que conviene a los intereses españoles. Cf. carta a Manuel Acevedo, París, 10 febrero 1832, cit. en Juan Uría Riu: «Flórez Estrada en París 1830-1834», Archivum, V, 1, 1955, p. 15. 
ro nada anarquista. Partidario de D. Pedro y de la Unión Ibérica. Si se le ve con frecuencia rodeado de realistas lo hace para disimular mejor. A Mellado le dice que el comisionado que vaya a ver a $D$. Pedro llevará mucho dinero y letra abierta - es decir, con la cantidad en blanco-como si fuera un embajador. A nuestros revolucionarios estas visiones debieran parecerles de ensueño.

Pero el de las 10 y media tiene un problema: no quiere que Sierra se relacione con Mestre, ni que tropiece con el Taller de la Unión. El será el único que participará de todo, aunque su trabajo le cuesta, y sus sudores, por el miedo de ser descubierto. Mestre y Villalonga acaban descubriendo no al de las 10 y media, sino a Sierra, y en seguida dudan de su honorabilidad. ¿Será Sierra agente de D. Pedro o del Gobierno español? Para averiguarlo se reunieron Mestre, Villalonga y el de las 10 $y$ media y discutieron tres proposiciones: $1 .^{\mathrm{a}}$, que Sierra se preste a estar encerrado en un cuarto, dejándoles a ellos el dinero o letras, asegurándole sólo el pago de las pequeñas inversiones que necesite. El de las lo y media se opuso, y fue desechada. 2. a , asesinar a Regato, y si Sierra es masón, comunicarle en una plancha cerrada los nombres supuestos de los hermanos asesinos, a fin de que vea que nos proponemos el escarmiento de los pícaros. También el de las 10 y media consiguió retirar esta propuesta, extraña y no bien comprensible. $3 .^{a}$, se le dirá que se necesitan 1.000 duros para urgencias, una de ellas la de tener que sacar de una casa 200 fusiles, carabinas y otras armas, ocultas desde el año pasado, para mandarlas a una provincia. Se pensó en decirle que se trataba de la casa del General Morillo, pero luego se prefirió hablar de una casa extramuros de la Puerta de Alcalá. La prueba consistía en estudiar las reacciones de Sierra: se aprobó (marzo 1832).

Pero al parecer no hizo falta recurrir a estas ordalías. Se supo que Sierra era inseparable de Valdés el de los Gatos, al que se tenía indudablemente por agente de policía del Gobierno: Mestre exigió de los otros el juramento de asesinar a Sierra, y Villalonga y el de las 10 y media lo prestaron. Ignoro el final de esta aventura. En realidad, Sierra Mariscal había servido en Guardias de Corps, fue perseguido y obligado a emigrar. Estando en Londres, en compañía de su hermano mayor también emigrado y hombre de mucho dinero, trataron Torrijos y otros compatriotas de hacer una incursión en la Península, que a Sierra le pareció desatinada, por lo que la denunció a Cea Bermúdez. En premio, el Rey le mandó el despacho de Capitán. Pasó a Francia y D. Pedro le confió una misión en Madrid, adonde fue con pasaporte de Ofalia. Esto según lo que el propio Sierra le confesó a Mellado, pero sabemos además que 
estuvo en Lisboa en 1826-27 con dinero ${ }^{153}$, que volvió a Río de Janeiro, donde se hallaba todavía en marzo de 1828 dispuesto a salir hacia Londres, siempre en contacto con el Gobierno español ${ }^{154}$.

Mediante la extraordinaria aventura de sus agentes secretos y múltiples policías, pudo quizá el Gobierno español evitar una revolución que parecía próxima. No pudo naturalmente evitar la muerte de Fernando VII en septiembre de 1833 , pero el triunfo relativo de los liberales no supuso el triunfo de la ansiada revolución. Los mitos persistían. Francisco Díaz Morales se hallaba refugiado en Marsella, junto a Vigo, Valdés y otros, «que aspiran a volver sus miras hacia este Emperador como joven enérgico para acabar con el Gobierno de S. M. la Reina: y que aunque el General Mina no se presentaba favorable a este plan, le despreciaban y se pasarían sin él», según un fragmento de carta de Díaz Morales copiado por Evaristo Pérez de Castro, en sus despachos de 16 y 19 de julio de 1834 sobre la llegada a Barcelona del paquebote francés Comercio de Lila, procedente de Marsella, en el que viajan el revolucionario español y José M. ${ }^{a}$ de Lemos, joven médico portugués de 28 años. No se sabe dónde han desembarcado. Pérez de Castro no oculta su pensamiento: «Si tratan de atizar el fuego y fraguar revoluciones, no los cree mi moral dignos de compasión ni miramientos» ${ }^{155}$.

Unos días después la Reina Gobernadora mandaba detener, por el delito de conspiración, a D. Juan Romero Alpuente, D. Lorenzo Calvo de Rozas, D. Juan Olavarría y otros -entre ellos el general Palafox-. La orden věnía firmada en Palacio el 23 de julio de 1834 por Francisco Martínez de la Rosa, el antiguo Rosita la Pastelera del Trienio. Se trataba de la conjuración de los Isabelinos, urdida al parecer por Eugenio de Aviraneta, que planeaba un golpe de mano contra la Reina para ins-

153 Cf. Fernández Martín, op. cit., en nota 39, pp. 42-3 (un tal Sierra, comerciante español). Parece que Sierra llevaba además una extraña misión: Casa Irujo le encomendaba averiguar si el Gobierno español pensaba enviar tropas a Portugal, y en caso afirmativo que lo avisase inmediatamente, pues el banquero Aguado pensaba hacer así un gran negocio. Casa Irujo invita a Sierra a que saque partido de los 25.000 duros que tiene en su poder, pero la contestación es que ese dinero tiene destino fijo (datos del agente de las 10 y media, 12 marzo 1832).

154 Cf. despacho de Ofalia a González Salmón, Lòndres, 21 marzo 1828, en Escritos, página 611 .

155 Cf. AHN, Estado, leg. 5435-3. Los dos textos transcritos pertenecen al despacho del 19 julio 1834. 
taurar en España el liberalismo. Pero ésta es ya otra historia ${ }^{156}$, la de Espronceda, Villalta, Orense, etc. Y la matanza de los frailes es también otra historia.

156 Cf. Juan Romero Alpuente: Exposición dirigida a S. M. la Reina Gobernadora, M., Oficina de Ortega, 1834, y Pío Baroja: Aviraneta o la vida de un conspirador, M., Espasa-Calpe, 1964. 